\title{
Reference quality upper-air measurements: GRUAN data processing for the Vaisala RS92 radiosonde
}

\author{
R. J. Dirksen ${ }^{1}$, M. Sommer ${ }^{1}$, F. J. Immler ${ }^{1, *}$, D. F. Hurst ${ }^{2,3}$, R. Kivi ${ }^{4}$, and H. Vömel ${ }^{1}$ \\ ${ }^{1}$ Deutscher Wetterdienst, Meteorologisches Observatorium Lindenberg, Richard-Aßmann-Observatorium, \\ Am Observatorium 12, 15848, Lindenberg/Tauche, Germany \\ ${ }^{2}$ Global Monitoring Division, NOAA Earth System Research Laboratory, Boulder, CO, USA \\ ${ }^{3}$ Cooperative Institute for Research in Environmental Sciences, University of Colorado, Boulder, CO, USA \\ ${ }^{4}$ Finnish Meteorological Institute, Sodankylä, Finland \\ "now at: European Commission, Brussels, Belgium
}

Correspondence to: R. J. Dirksen (ruud.dirksen@dwd.de)

Received: 6 March 2014 - Published in Atmos. Meas. Tech. Discuss.: 11 April 2014

Revised: 6 September 2014 - Accepted: 29 October 2014 - Published: 18 December 2014

\begin{abstract}
The GCOS (Global Climate Observing System) Reference Upper-Air Network (GRUAN) data processing for the Vaisala RS92 radiosonde was developed to meet the criteria for reference measurements. These criteria stipulate the collection of metadata, the use of well-documented correction algorithms, and estimates of the measurement uncertainty. An important and novel aspect of the GRUAN processing is that the uncertainty estimates are vertically resolved. This paper describes the algorithms that are applied in version 2 of the GRUAN processing to correct for systematic errors in radiosonde measurements of pressure, temperature, humidity, and wind, as well as how the uncertainties related to these error sources are derived. Currently, the RS92 is launched on a regular basis at 13 out of 15 GRUAN sites. An additional GRUAN requirement for performing reference measurements with the RS92 is that the manufacturerprescribed procedure for the radiosonde's preparation, i.e. heated reconditioning of the sensors and recalibration during ground check, is followed. In the GRUAN processing however, the recalibration of the humidity sensors that is applied during ground check is removed. For the dominant error source, solar radiation, laboratory experiments were performed to investigate and model its effect on the RS92's temperature and humidity measurements. GRUAN uncertainty estimates are $0.15 \mathrm{~K}$ for night-time temperature measurements and approximately $0.6 \mathrm{~K}$ at $25 \mathrm{~km}$ during daytime. The other uncertainty estimates are up to $6 \%$ relative humidity for humidity, $10-50 \mathrm{~m}$ for geopotential height, $0.6 \mathrm{hPa}$ for
\end{abstract}

pressure, $0.4-1 \mathrm{~m} \mathrm{~s}^{-1}$ for wind speed, and $1^{\circ}$ for wind direction. Daytime temperature profiles for GRUAN and Vaisala processing are comparable and consistent within the estimated uncertainty. GRUAN daytime humidity profiles are up to $15 \%$ moister than Vaisala processed profiles, of which two-thirds is due to the radiation dry bias correction and onethird is due to an additional calibration correction. Redundant measurements with frost point hygrometers (CFH and NOAA FPH) show that GRUAN-processed RS92 humidity profiles and frost point data agree within $15 \%$ in the troposphere. No systematic biases occur, apart from a $5 \%$ dry bias for GRUAN data around $-40^{\circ} \mathrm{C}$ at night.

\section{Introduction}

For decades radiosondes have proven extremely successful in delivering essential information on the state of the atmosphere by measuring high-vertical-resolution profiles of temperature, water vapour, wind, and pressure up to about $40 \mathrm{~km}$. These data provide important initializations to numerical weather prediction models and are also very valuable for the validation of satellite observations. With approximately 1000 radiosondes being launched around the world each day, this constitutes a vast and valuable set of data which has great potential for climate research. Profile data from radiosoundings are motivated largely by short-term applications such as (numerical) weather prediction. Frequent 
changes in the design and characteristics of radiosondes by their manufacturers has unfortunately introduced jumps and drifts in data records that hinder long-term trend analysis (Elliott, 1991). Furthermore, differences between radiosondes from different manufacturers complicate the comparison of data records from different sources (Moradi et al., 2013). It remains a major challenge to make radiosounding records suitable for long-term climate monitoring and trend detection. Several attempts have been undertaken to homogenize data records from various sources, e.g. Free et al. (2005), Sherwood et al. (2008), Thorne et al. (2011), and Haimberger et al. (2012) for temperature records and Durre et al. (2009), McCarthy et al. (2009), and Dai et al. (2010) for humidity records.

In order to detect and study trends in essential climate variables (ECVs; see Bojinski et al., 2014) like temperature and humidity, the instrumental long-term stability should be better than $0.1 \mathrm{~K}$ and $2 \%$ relative humidity $(\mathrm{RH})$ for the temperature and humidity measurements, respectively (GCOS112, 2007). For this purpose the GCOS Reference Upper-Air Network (GRUAN) was established, with the goal of creating a network of selected sites around the world where reference measurements of the upper atmosphere are performed (Seidel et al., 2009). Immler et al. (2010) laid out the definition for a reference measurement that requires traceability, full metadata description, and the best possible characterization of measurement uncertainties. Traceability means that measurement conditions and operational procedures are documented and that the calibrations and corrections, which are applied in the data processing, are properly documented and disclosed to the scientific user. Traceability also means the application of a manufacturer-independent ground check to detect possible instrument changes and to independently assess the calibration uncertainty. Black-box software or proprietary algorithms should never be used in reference observations. The philosophy behind these requirements is to enable future reprocessing if improved corrections become necessary, and to prevent the inclusion of manufacturerdependent biases in climate records. A GRUAN data product must be open, documented in peer-reviewed literature, traceable to SI standards, and must contain best possible estimates of the measurement uncertainties, where the treatment of errors and uncertainties is outlined in the "Guide to the expression of uncertainty in measurement" by the working group 1 of the Joint Committee for Guides in Metrology (JCGM/WG 1, 2008, hereafter). An important and unique aspect of a GRUAN product is that the uncertainty estimates are given for each datum of a collection; i.e. uncertainties are vertically resolved for profiles and temporally resolved for time series.

In this paper we present the GRUAN data-processing methods (version 2) for the Vaisala RS92 radiosonde. The RS92 was introduced in 2003 and currently has a global market share of approximately $30 \%$. Numerous studies and field campaigns have investigated its performance and accuracy.
This paper is structured as follows: Sect. 2 discusses the treatment of uncertainties, Sect. 3 gives a brief overview of the Vaisala RS92 sonde. An overview of the set-up of the GRUAN data processing is given in Sect. 4. The corrections for temperature and humidity are discussed in Sects. 5 and 6 , respectively. In Sect. 7 GRUAN-processed data is compared to profile data processed by Vaisala software, as well as to frost point hygrometer data. The measurement of the geopotential height is discussed in Sect. 8, and the processing of wind data is the subject of Sect. 9. Finally, Sect. 10 presents a summary and recommendations.

\section{Errors and uncertainties}

For the treatment of errors and uncertainties we follow the approach outlined in the "Guide to the expression of uncertainty in measurement" by the working group 1 of the Joint Committee for Guides in Metrology (JCGM/WG 1, 2008). Following their definition, an error is the difference between the measured value and the "true" value of the measurand, resulting from imperfections in the measurement. The uncertainty is an estimate of the standard deviation and characterizes the range of values (dispersion) that can be expected for a measurement. For normally distributed errors the standard deviation is given as $1 \sigma$, which represents $67 \%$ of the distribution ( $2 \sigma$ and $3 \sigma$ represent 95 and $99.7 \%$ of the distribution, respectively).

Measurement errors can be classified as random or systematic. The effect of a random error can be reduced by increasing the number of measurements, and its average value will asymptotically approach 0 . A systematic error, however, will persist regardless of the number of observations, introducing a bias to the measurement. An example of a random error is the noise of the temperature sensor readings, whereas an example of a systematic error is the warm bias introduced by daytime heating of the temperature sensor by solar radiation. Systematic errors typically persist among independent but repetitive measurements, thereby introducing biases in long-term data records. When systematic errors are properly characterized, they can be removed with confidence, which reduces the uncertainty of the measurement. However, since corrections are never exact for varying conditions, the correction itself may introduce a new random error, and a residual uncertainty associated with the correction will remain.

The classification into random and systematic errors is closely related to the terms uncorrelated and correlated uncertainties, respectively. Uncorrelated uncertainties can be reduced by increasing the number of observations. This is not the case for correlated uncertainties that stem from systematic errors because the repetition of a biased measurement does not reduce its systematic uncertainty. The majority of the GRUAN corrections for the RS92 data processing aim to reduce systematic errors in the measurements, and the associated uncertainties are correlated. 
Smoothing or filtering can reduce the noise of an individual radiosounding profile, but these only remove random errors. Correlated uncertainties due to systematic errors will persist in the smoothed profile. The statistical noise of a profile before smoothing represents the uncorrelated uncertainty. A mathematical description of uncertainties is given in Appendix A.

An important aspect of the GRUAN data product is the availability of a vertically resolved best-estimate uncertainty. Comparisons with other instruments are essential in identifying and possibly quantifying systematic errors. An independent measurement of the same variable allows for the verification of both the data processing and the uncertainty quantification. Measurement redundancy also is important during changes of measurement system and/or operations procedure.

\section{Description of the RS92 radiosonde}

The Vaisala RS92 radiosonde, shown in Fig. 1, measures vertical profiles of pressure, temperature, and humidity (PTU) from ground to the balloon-burst altitude limit of approximately $40 \mathrm{~km}$. The RS92 is equipped with a wire-like capacitive temperature sensor ("Thermocap"); two polymer capacitive moisture sensors ("Humicap"); a silicon-based pressure sensor; and a GPS receiver to measure position, altitude, and winds. The RS92 transmits sensor data at 1-second intervals, which are received, processed, and stored by the DigiCora ground station equipment.

A hydrophobic, reflective coating is applied to the sensor boom and the temperature sensor to reduce the RS92's sensitivity to solar radiation, and to reduce the deposition of water or ice when flying through clouds.

The GPS receiver on the RS92 transmits its position as $x y z$ coordinates in the WGS-84 (World Geodetic System 1984) system. These $x y z$ coordinates are then converted into latitude, longitude, and altitude data by the DigiCora system, while using the readings of the station GPS antenna as a reference for determining the geometric altitude of the radiosonde.

The sensors of the assembled radiosonde are calibrated in Vaisala's CAL4 calibration facility (Vaisala, 2002). The CAL4 contains PTU reference sensors that are recalibrated at regular intervals against standards that are traceable to NIST (for pressure and temperature) and its Finnish equivalent, MIKES (for humidity). The respective operating ranges and accuracies of the PTU sensors are $3( \pm 0.6)$ to $1080( \pm 1) \mathrm{hPa}$, $-90( \pm 0.5)$ to $60( \pm 0.5){ }^{\circ} \mathrm{C}$, and $0( \pm 5)$ to $100( \pm 5) \% \mathrm{RH}$, respectively (Vaisala, 2007).

Corrections reduce errors in the temperature and humidity due to solar radiation, time-lag of the RH sensor, and sensor recalibration during the pre-flight ground check. Furthermore, corrections are applied for spurious noise like temperature spikes (Shimizu and Hasebe, 2010). Most of these

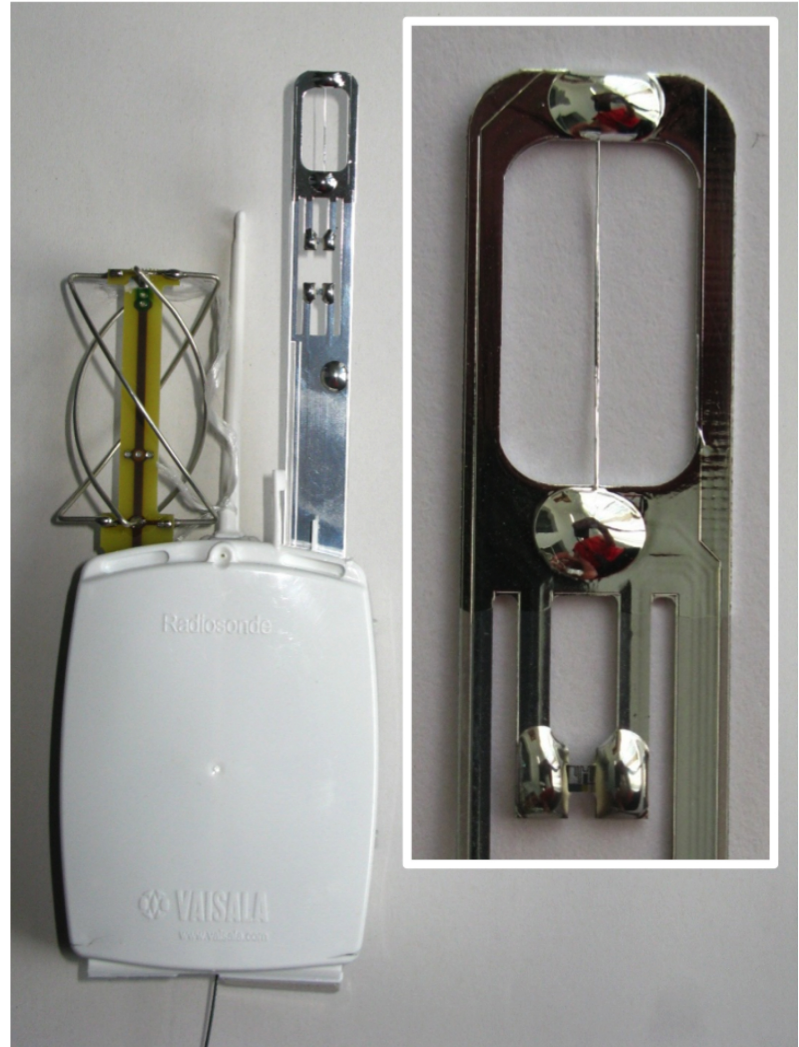

Figure 1. Photograph of the RS92 radiosonde showing the GPS antenna on the left and the sensor boom on the right. The inset shows the magnified tip of the sensor boom with the wire-shaped temperature sensor and one of the humidity sensors.

correction algorithms are proprietary and are not disclosed to the user. An overview of relevant modifications in the RS92 hardware and the processing software is available at the Vaisala data continuity website (Vaisala continuity website, 2013).

The RS92 has participated in a number of campaigns and intercomparisons (Whiteman et al., 2006; Nash et al., 2006, 2011; Calbet et al., 2011; Leblanc et al., 2011; Bock et al., 2013). Campaigns have identified error sources for the RS92 such as radiation dry bias (Vömel et al., 2007b), sensor time-lag (Miloshevich et al., 2004), and a temperaturedependent calibration error for the humidity sensors (Vömel et al., 2007b; Miloshevich et al., 2009).

\subsection{Ground check}

The manufacturer's operational procedure demands that prior to flight a ground check is performed. During this check the sensor boom is inserted into a calibration unit (GC25) and the sensors are heated to remove contaminants that introduce a dry bias in the humidity measurements ("reconditioning"). In addition, a one-point recalibration is applied to the PTU, based on comparing the temperature and pressure sen- 
sors to a PT100 temperature sensor and the station barometer, respectively, and recording the humidity sensor readings in a dry zone over a bed of desiccant. In the GRUAN processing the recalibration of the humidity sensor is reversed (Sect. 6.2).

\section{Data processing}

The sounding data and metadata are submitted to the GRUAN database using a GRUAN-provided software tool, the RsLaunchClient (Sommer, 2014), that checks the completeness and integrity of the metadata. The metadata contain all information relevant for (re)processing a radiosounding and, in addition to all instrument parameters, include information such as payload configuration, balloon-type and weight, and results of the pre-flight ground checks. This inclusion of metadata complies with the GRUAN philosophy that sounding data plus extensive metadata constitute a traceable measurement.

The GRUAN processing is based on the uncorrected, 1second-resolution raw data contained in the FRAWPTU table for PTU and GPSDCC_RESULT for the GPS data, which are both contained in the .DC3DB sounding file.

The processing steps are shown in Fig. 2. The left block in Fig. 2 consists of preparing, collecting, and joining the measurement and metadata, so that all relevant parameters are available. This involves steps like determining the exact moment of launch, analysis of the pre-launch checks, calculation of geographical coordinates from the GPS data, and the merging of the data from both humidity sensors. An important step in the pre-processing is the reversal of the recalibration of the humidity sensors as discussed in Sect. 3.1. The GRUAN correction algorithms are indicated in the right block in Fig. 2, which shows the order in which the corrections are applied. Before and after the application of the GRUAN corrections, the sounding data are subjected to quality control (QC), which is discussed in Sect. 4.1. The GRUAN data product is stored in NetCDF (Network Common Data Form) format, and processed soundings that have passed quality control are disseminated through the NCDC (National Climatic Data Center) FTP (File Transfer Protocol) server (www.gruan.org/data). A description of the GRUAN data product format is given by Immler and Sommer (2014). The current GRUAN RS92 data product is version 2. This was released in September 2012, and the descriptions in this paper are specific to this version.

\subsection{Quality control}

The initial quality control verifies that the readings of the PTU sensors during the ground check are within pre-defined limits before GRUAN corrections are applied. This includes checking the difference between the two humidity sensors. For the data to be processed, the corrections determined in

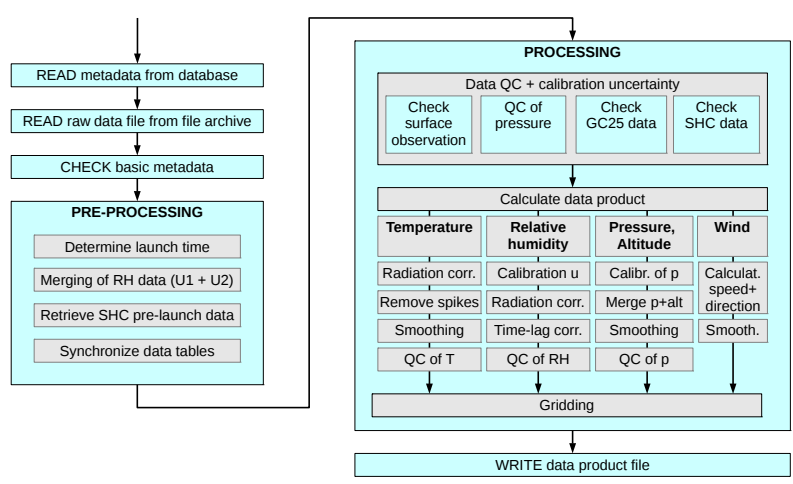

Figure 2. Schematic representation of the data flow, processing steps, quality control (QC), and correction algorithms applied in the GRUAN processing. SHC denotes standard humidity chamber (see Sect. 3.1). In the final step before the data are written to file, "gridding", the temporal sampling of the profile is reduced from $1 \mathrm{~s}$ to an integer number of choice. In the GRUAN processing as described in this paper, the temporal sampling remains $1 \mathrm{~s}$.

the GC25 must be less than $1 \mathrm{~K}$ for $T, 1.5 \mathrm{hPa}$ for $P$, and less than $2 \% \mathrm{RH}$ for $U$. In the standard humidity chamber (SHC) the readings should be within $5 \% \mathrm{RH}$ of the ambient humidity. During ground check in the GC25 and the SHC, the difference between $U_{1}$ and $U_{2}$ should be less than $1.5 \%$ RH.

After the GRUAN corrections have been applied, a second quality control step checks that profile data are within valid ranges, establishes the number of valid data points ( $>95 \%$ ), and ensures that the GRUAN uncertainty estimates are within the Vaisala-provided uncertainties.

\section{Temperature}

\subsection{Introduction}

The temperature sensor of the RS92 radiosonde consists of a temperature-dependent capacitive sensor (Thermocap) (Turtiainen et al., 1995). The sensor wire is covered with a reflective, hydrophobic coating to reduce solar heating and systematic errors from evaporative cooling by any water or ice collected during passage through clouds. With an operating range from -90 to $+60^{\circ} \mathrm{C}$, Vaisala (2007) quotes an accuracy of better than $0.5 \mathrm{~K}$.

In this section, several sources of error (systematic and random) for the temperature measurements are discussed together with the respective GRUAN correction algorithms. The dominant systematic error is due to solar radiative heating. Using a heat transfer model, the radiative error for the RS90 temperature sensor was estimated to be approximately $0.5 \mathrm{~K}$ at $35 \mathrm{~km}$ (Luers, 1997). This number is comparable to the correction of up to $0.63 \mathrm{~K}$ at $5 \mathrm{hPa}$ that was applied by the DigiCora software (prior to version 3.64) in the processing of RS92 routine soundings until 2010, when this 
was increased to $0.78 \mathrm{~K}$ (Vaisala continuity website, 2013). The 8th World Meteorological Organization (WMO) radiosonde intercomparison in Yangjiang, China, indicates that the Vaisala-corrected temperature measurements of the RS92 may exhibit a warm bias of up to $0.2 \mathrm{~K}$ (Nash et al., 2011). A recent comparison between radiosoundings and spaceborne GPS radio occultation measurements reports a $0.5-$ $1 \mathrm{~K}$ warm bias at $17 \mathrm{hPa}$ for Vaisala-corrected RS92 temperature profiles (Sun et al., 2013). The accuracy of the satelliteretrieved temperature is approximately $0.2-0.3 \mathrm{~K}$ in the middle stratosphere (Kursinski et al., 1997; Hajj et al., 2004).

The GRUAN radiation correction, discussed in Sect. 5.2, relies on laboratory experiments and radiative transfer calculations to estimate the actinic flux on the sensor. Laboratory work has determined the relation between temperature error and actinic flux as a function of pressure and ventilation. Other sources of error include temperature spikes (Shimizu and Hasebe, 2010) due to patches of warm air coming off the sensor housing and the balloon (Sect. 5.3), evaporative cooling of the wetted sensor after exiting a cloud (Sect. 5.4), and sensor time-lag (Sect. 5.5). The last two effects are not corrected because no appropriate correction algorithm is available for evaporative cooling, although affected data points should be flagged and the impact of time-lag is considered negligible (see Sect. 5.5).

\subsection{Radiation error}

During daytime the radiosonde sensor boom is heated by solar radiation, which introduces biases in temperature and humidity. The net heating of the temperature sensor depends on the amount of absorbed radiation and on the cooling by thermal emission and ventilation by air flowing around the sensor. Luers (1990) used customized radiative transfer calculations and detailed information on the actual cloud configuration to accurately compute the radiation temperature error for selected soundings. Such information on cloud configuration and surface albedo is usually not available for each individual sounding; in view of the large amount of data that is collected within the GRUAN network, the processing makes use of generalized assumptions regarding these parameters. The radiation error is corrected for every data point of the profile by estimating the radiation flux on the sensor from pre-calculated radiative transfer simulations (see Sect. 5.2.2). This is fed to a correction model (Eq. 1) which contains the sensor's response to radiation as a function of flux, pressure, and ventilation speed, which was determined using the experiments discussed in Sect. 5.2.1. The correction model yields the estimated vertically resolved error to the temperature, based on the estimated actinic flux, which is subtracted from the measured temperature profile to yield the corrected ambient temperature. In the current version of the processing, the actual correction that is applied is the mean of the GRUAN and the Vaisala correction (Sect. 5.2.5).
The GRUAN correction only corrects for the daytime radiation error because our experiments do not yield information on radiative coupling with a cold background which causes the night-time cooling. Longwave radiative cooling is relatively small compared to shortwave heating, as is illustrated by the $0.04 \mathrm{~K}$ cooling at $5 \mathrm{hPa}$ that is assumed by the Vaisala radiation correction for night-time measurements (Vaisala continuity website, 2013). For the correction of the nighttime cooling error of the temperature sensor we employ the Vaisala correction (Sect. 5.2.5).

\subsubsection{Radiation experiments}

The sensor's response to radiation has been measured to determine the radiative heating correction of the RS92 temperature data. For these experiments the radiosonde sensor boom is mounted in a custom-built vacuum chamber underneath a quartz plate lid where it can be illuminated by a known radiation source.

The experiments are typically performed outdoors, using the Sun as the light source. The vacuum chamber is oriented perpendicular to the incoming solar rays, and a shutter is used to control the illumination of the sensor. A rotating fan serves to mimic the ventilation of the sensor during flight, and the pressure can be controlled between $4 \mathrm{hPa}$ and ambient pressure. Background temperature and pressure inside the chamber are measured by a second, shaded RS92 sonde. The solar irradiance is measured by an external pyranometer. The flux on the sensors can be attenuated by placing a grey filter in front of the aperture of the shutter. During the experiment the sensor is illuminated for 30 to $180 \mathrm{~s}$, depending on pressure, followed by an equally long cool-down interval with the shutter closed. This open-and-close cycle is repeated at least four times for each pressure and ventilation speed. Ventilation speeds of 2.5 and $5 \mathrm{~m} \mathrm{~s}^{-1}$ were employed, with an uncertainty of $1 \mathrm{~ms}^{-1}$ due to the unknown characteristics of the flow around the temperature sensor in our set-up.

Figure 3 shows a typical example of the response of the temperature sensor to solar irradiance at $100 \mathrm{hPa}$ ambient pressure: a quick rise of temperature followed by a slower levelling-off. The initial fast rise is due to the small thermal mass of the sensor. The mechanism behind the subsequent slow rise is not yet fully established. It is possibly connected to the heating of the sensor boom, but it is unclear to what extent this effect contributes to the heating of the temperature sensor in flight. Here, the radiation temperature error for a certain pressure and ventilation speed is determined from the difference between the sensor temperature approximately $20 \mathrm{~s}$ after opening the shutter and from the average background level immediately before opening the shutter.

Version 2 of the GRUAN processing relates the measured temperature change $\Delta T$ to actinic flux $I_{\mathrm{a}}$ (the modelling of $I_{\mathrm{a}}$ is explained in Sect. 5.2.2), ambient pressure $p$, and ventilation speed $v$ as 


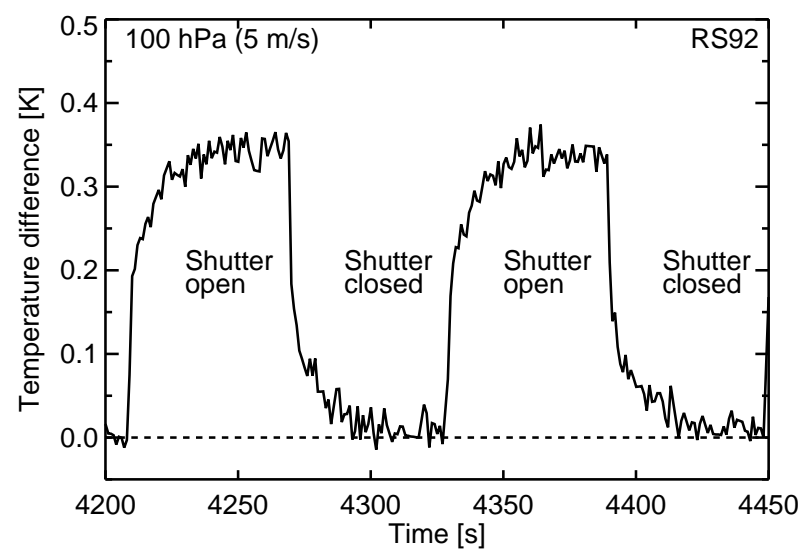

Figure 3. Temperature difference between the illuminated and the shaded RS92 temperature sensors. The direct solar irradiance, as monitored by an external pyranometer, was approximately 800 $( \pm 10) \mathrm{W} \mathrm{m}^{-2}$ during the experiment. The pressure was $100 \mathrm{hPa}$, and the ventilation speed $5 \mathrm{~m} \mathrm{~s}^{-1}$.

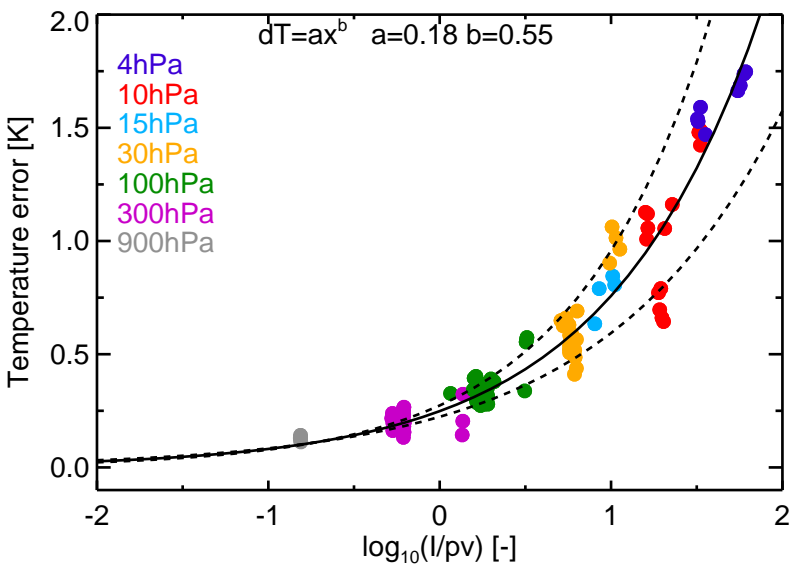

Figure 4. Results of radiation experiments performed at various ventilation speeds, $v$, and pressures $p$. Ventilation speeds are 2.5 and $5 \mathrm{~ms}^{-1}$. The solar irradiance $I$ was monitored externally and was additionally varied by the use of grey filters. The solid black line indicates the best fit to the data, whereas the dashed lines indicate the estimated uncertainty range of the fit.

$$
\Delta T\left(I_{\mathrm{a}}, p, v\right)=a \cdot x^{b} \quad \text { with } x=\frac{I_{\mathrm{a}}}{p \cdot v},
$$

with fit parameters $a$ and $b$. The results of the radiation experiments at various pressures, ventilation speeds, and irradiance levels are shown in Fig. 4. A statistical fit to the data yields $a=0.18( \pm 0.03)$ and $b=0.55( \pm 0.06)$.

\subsubsection{Streamer radiative transfer model}

To relate the measured temperature error in the laboratory with that encountered during a sounding, the actinic flux has to be modelled. The total actinic flux onto the temperature sensor in flight is the sum of the direct sunlight and of the diffuse background which results from light that is scattered by the surface and the atmosphere:

$I_{\mathrm{a}}=g I_{\mathrm{s}}+D_{\mathrm{d}}+D_{\mathrm{u}}$,

with $I_{\mathrm{S}}$ being the solar irradiance, and $D_{\mathrm{d}}$ and $D_{\mathrm{u}}$ the diffuse downward and upward welling radiation respectively. Due to the fact that the RS92 temperature sensor is a wire rather than a sphere, the direct solar flux onto the sensor depends on its orientation. The geometry factor $g$ accounts for the reduction of the exposed area of the temperature sensor due to spinning of the radiosonde, which causes the orientation of the sensor wire to cycle between being parallel and perpendicular to the solar rays. Currently, a value of 0.5 is used for $g$, but this may change in the next version of the GRUAN processing. The actinic flux $I_{\mathrm{a}}$ is estimated from simulations by the Streamer model (Key and Schweiger, 1998), which is used to calculate $I_{\mathrm{s}}, D_{\mathrm{d}}$, and $D_{\mathrm{u}}$ integrated for the visible and near-IR wavelength range between 0.28 and $4 \mu \mathrm{m}$ for solar elevation angles $\phi=30,72$, and $90^{\circ}$, and for various cloud scenarios (Table 1). For the cloudy scenario two cloud layers are included: a wet cloud at the top of the boundary layer and an ice cloud just below the tropopause region, which is typical for midlatitude cloudy conditions. However, this cloud configuration can also be used to correct the radiation temperature error for soundings performed in other climate regions. In the troposphere the radiation error is small, meaning that inaccuracies in the altitude of the modelled clouds have only a minor impact on that part of the temperature profile. In the cloud-free stratosphere, where the radiation error is key, the uncertainty in the actinic flux is dominated by the cloud configuration and surface albedo rather than by the altitude of the underlying cloud layers.

The vertical distributions of water vapour and ozone in the modelled atmosphere are representative of the midlatitude case. The fluxes in the output of a Streamer model run are given with respect to reference surfaces parallel to the Earth's surface, and consequently the Streamer-calculated solar irradiance represents the component perpendicular to the Earth's surface. In order to retrieve the solar irradiance $I_{\mathrm{S}}$ on the sensor wire, the Streamer-calculated solar irradiance has to be divided by $\sin \phi$, with $\phi$ being the solar elevation angle.

Because radiative transfer calculations are computationally expensive, these are performed in advance for the generalized configurations listed in Table 1 , and the simulated $I_{\mathrm{a}}$ values are stored in a two-dimensional look-up table with its dimensions being the cloud configuration and the solar elevation angle. At a given elevation angle, $I_{\mathrm{a}}$ is given by linear interpolation between the reference points $(\phi=30,72$, and $90^{\circ}$ ) in the look-up table with the additional constraint that $I_{\mathrm{a}}=0$ for $\phi \leq-5^{\circ}$. At $\phi=-5^{\circ}$ the Sun is so far below the horizon that even at $35 \mathrm{~km}$ the radiosonde will not be irradiated. In the current version of the processing the effect of the curvature of the atmospheric layers for angles below $30^{\circ}$ on the actinic flux is not taken into account. 
Table 1. Settings for simulations with the Streamer model.

\begin{tabular}{lcccc}
\hline Date & $\begin{array}{c}\text { Solar elevation angle } \\
{\left[{ }^{\circ}\right]}\end{array}$ & $\begin{array}{c}\text { Cloud layer 1 } \\
{[\mathrm{km}]}\end{array}$ & $\begin{array}{c}\text { Cloud layer 2 } \\
{[\mathrm{km}]}\end{array}$ & Surface albedo \\
\hline 21 Jun & 90 & - & - & $\approx 0.27$ \\
21 Jun & 72 & - & - & $\approx 0.27$ \\
13 Nov & 30 & - & - & $\approx 0.27$ \\
21 Jun & 90 & $4-6$ & $7-10$ & $\approx 0.27$ \\
21 Jun & 72 & $4-6$ & $7-10$ & $\approx 0.27$ \\
13 Nov & 30 & $1-2$ & $8-11$ & $\approx 0.27$ \\
\hline
\end{tabular}

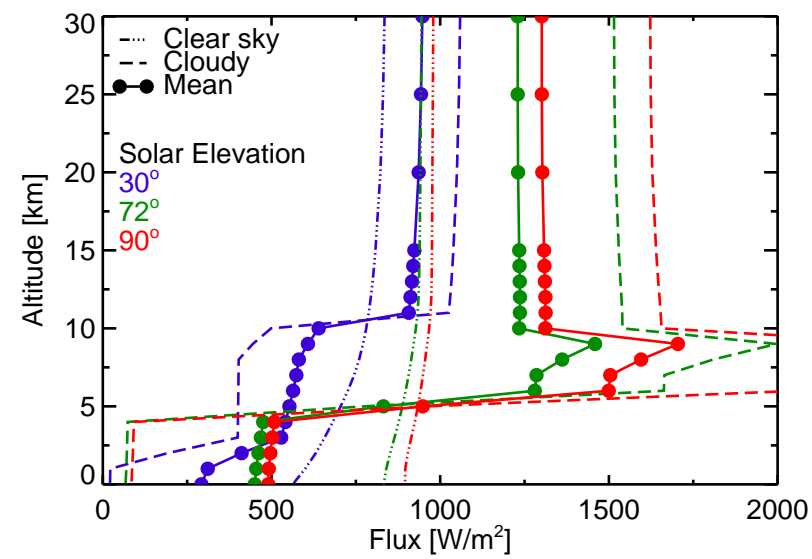

Figure 5. Vertical profiles of the total actinic flux on the sensor for solar elevation angles of 30,72 , and $90^{\circ}$. The actinic flux is the sum of the direct sunlight and diffuse background. The mean actinic flux is the average of the cloud-free (dashed-dotted line) and cloudy (dashed line) scenario. The kinks below $10 \mathrm{~km}$ result from the cloud layers around 5 and $8 \mathrm{~km}$ used in the simulations.

Figure 5 shows that above the tropopause the simulated actinic flux $I_{\mathrm{a}}$ is fairly constant with altitude, due to negligible atmospheric scatter and the absence of clouds in the stratosphere. The increase of $I_{\mathrm{a}}$ with elevation angle largely results from diffuse radiation and radiation reflected from the surface; the solar irradiance remains constant. The albedo is highly variable due to its dependence on the scene and therefore is a major source of uncertainty in the simulated actinic flux. The surface albedo ranges from less than $10 \%$ for a dark ocean surface up to $90 \%$ for a fresh snow cover, whereas cloud albedo typically ranges from 40 to $80 \%$. The importance of the albedo is illustrated by the increase of the actinic flux from approximately $1000 \mathrm{~W} \mathrm{~m}^{-2}$ in the cloud-free case to approximately $1600 \mathrm{~W} \mathrm{~m}^{-2}$ in the presence of an underlying cloud layer. This increase solely results from the increase in upwelling radiation by the highly reflective cloud layer.

In the presence of a wet cloud $(\mathrm{RH}>99 \%)$ the assumed actinic flux between the surface and the cloud top is equal to that for the cloudy case; this only concerns the first few kilometres of the sounding where the radiation temperature error is small. This method is not employed at higher alti- tudes where the radiation error is significant, because relative humidity alone is not a reliable proxy for the presence of ice clouds (e.g. super-saturation). Currently no approach exists to explicitly use cloud and surface albedo information (e.g. climatology or coincident satellite observations) in the correction of the radiation temperature error. Instead, the cloudy and the cloud-free case represent the lower and upper limit for the actinic flux. Following Sect. 4.4.5 of JCGM/WG 1 (2008), $I_{\mathrm{a}}$ is assumed to be the average of the cloudy and the cloud-free case, and the uncertainty at $1 \sigma(k=1)$ for a rectangular a priori probability distribution bound by $I_{\mathrm{a}}$, cloudy

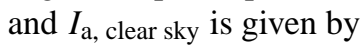

$u\left(I_{\mathrm{a}}\right)=\frac{\left|I_{\mathrm{a}, \text { cloudy }}-I_{\mathrm{a}, \text { clear sky }}\right|}{2 \sqrt{3}}$.

Due to spinning of the radiosonde in flight, the solar irradiance on the sensor wire cycles between 0 and maximum. In case of rapid spinning - i.e. more than, say, 10 revolutions per minute - the temperature rise due to the orientation should average out and should not introduce a mean bias in the temperature profile. Not knowing the instantaneous rotational rate leads to an increased uncertainty around the mean radiation bias. However, if the radiosonde rotates slowly, the orientation of the temperature sensor with respect to the Sun no longer averages out.

The orientation uncertainty and the associated temperature uncertainty only apply to the direct solar irradiance $I_{\mathrm{S}}$ because the temperature error from the diffuse (omnidirectional) background remains largely the same regardless of sensor orientation.

\subsubsection{Ventilation speed}

The correction of the radiation temperature error also depends on the ventilation speed $v$. Using the actual ascent rate leads to a more accurate radiation temperature correction when changes in the ascent speed occur, e.g. the slowing down of the balloon due to the temperature inversion at the tropopause (Gallice et al., 2011). In the GRUAN processing the actual ventilation speed is used, rather than assuming a fixed value. The actual ventilation speed is the sum of the ascent speed, which is derived from the altitude data, plus an additional contribution due to the sonde's pendulum motion. 


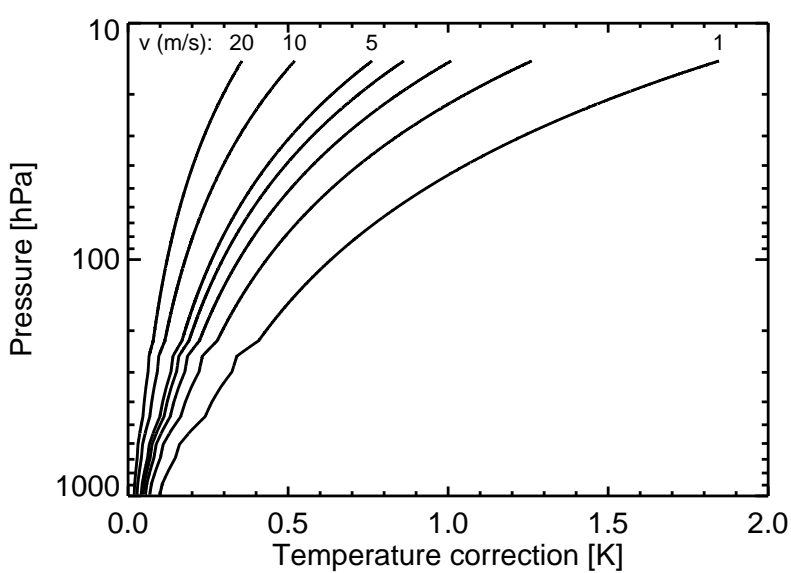

Figure 6. Profiles of the GRUAN radiation temperature correction for ventilation speeds between 1 and $20 \mathrm{~m} \mathrm{~s}^{-1}$. The correction was calculated for a radiosounding performed in Lindenberg on 17 September 2013 at 12:00 UTC. The kinks in the profiles between 900 and $200 \mathrm{hPa}$ result from the cloud configuration that was used in the Streamer simulations, with cloud layers between 4 and 6 and between 7 and $10 \mathrm{~km}$, which introduces jumps in the simulated radiation profile at the top of the cloud (see the dashed traces in Fig. 5). The maximum solar zenith angle during the sounding was $36.5^{\circ}$.

The increase of the ventilation due to the pendulum motion is estimated at $1 \mathrm{~m} \mathrm{~s}^{-1}\left( \pm 1 \mathrm{~m} \mathrm{~s}^{-1}\right)$ for $30 \mathrm{~m}$ unwinder length, assuming an amplitude of a few metres. Furthermore, another $1 \mathrm{~m} \mathrm{~s}^{-1}$ is added to the uncertainty of the ventilation speed as a consequence of the uncertainty of the flow around the temperature sensor during the radiation experiments, as was discussed in Sect. 5.2.1. The sensitivity of the radiation temperature correction to the ventilation speed is shown in Fig. 6. At the nominal ascent rate of $5 \mathrm{~m} \mathrm{~s}^{-1}$, a speed difference of $2 \mathrm{~m} \mathrm{~s}^{-1}$ leads to temperature errors ranging from $0.1 \mathrm{~K}$ at $100 \mathrm{hPa}$ up to $0.2-0.3 \mathrm{~K}$ at $10 \mathrm{hPa}$.

\subsubsection{Vaisala radiation correction}

The Vaisala correction for the radiation temperature error is available as a table for various pressures and solar elevation angles (Vaisala continuity website, 2013). In contrast to the GRUAN radiation correction, Vaisala also corrects for the night-time cooling of the temperature sensor through longwave radiative coupling with the cold background.

Until DigiCora version 3.64, released in 2011, the ascent speed was not used in the correction for the radiation temperature error (Vaisala continuity website, 2013).

\subsubsection{Averaged correction}

At this stage it is not clear which correction model, GRUAN or Vaisala, is more accurate; therefore the resulting correction for the radiation temperature error implemented in the GRUAN data product is the average of the two. The com- parison of both correction models, presented in Fig. 7, shows that below $25 \mathrm{~km}$ altitude the temperature correction based on the GRUAN radiation experiments and the Vaisala correction are similar although the Vaisala correction is consistently $<0.1 \mathrm{~K}$ larger than the GRUAN correction. Above $25 \mathrm{~km}$ the GRUAN correction rapidly exceeds the Vaisala correction, presumably due to a stronger pressure dependence at low pressures. Still both corrections are consistent, as the Vaisala lies within the uncertainty range of the GRUAN correction. The wiggles in the GRUAN correction profile are caused by variations in the recorded ascent speed, which are absent in the straight look-up table provided by Vaisala up to DigiCora version 3.63. In the absence of a GRUAN correction for night-time measurements, the Vaisala correction is used instead.

\subsection{Temperature spikes}

Spikes in the daytime temperature profile may result from air being heated by the radiosonde package, and possibly from passing through the warm wake of the balloon due to the pendulum motion of the payload (Tiefenau and Gebbeken, 1989; Shimizu and Hasebe, 2010). In the GRUAN data processing these temperature spikes are identified and removed from the profile in a two-step filtering process. First the temperature profile is smoothed by applying a low-pass digital filter with a cut-off frequency of $0.1 \mathrm{~Hz}$. Subsequently, data points for which the difference between the smoothed and the un-smoothed temperature exceeds a threshold are classified as spikes and are removed from the profile. This threshold is based on the statistical standard deviation of the smoothed data, using Eq. (A5). After the removal of these outliers the smoothing filter is applied again, and the spikes are replaced by interpolated values. Temperature spikes are only an issue at lower pressures; therefore the spike-removal algorithm is applied to data above the $500 \mathrm{hPa}$ level, and in the current version of the algorithm only warm spikes are detected and removed.

Due to the low-pass filter the temporal resolution of the temperature profile is reduced to approximately $10 \mathrm{~s}$ (corresponding to $50 \mathrm{~m}$ in the vertical), although the sampling remains at $1 \mathrm{~s}$. Figure 8 illustrates the removal of warm spikes from the daytime temperature profile. In this particular sounding $5 \%$ of the data points were affected by temperature spikes.

\subsection{Evaporative cooling}

When the radiosonde flies through a cloud, the temperature sensor will inevitably be coated with water or ice, which may introduce errors in the temperature measurements above the cloud due to evaporative cooling. In extreme cases this effect can cause the occurrence of apparent superadiabatic lapse rates (SLRs) in radiosonde profiles near cloud tops (Hodge, 1956). Inside the cloud, the condensate on the temperature 


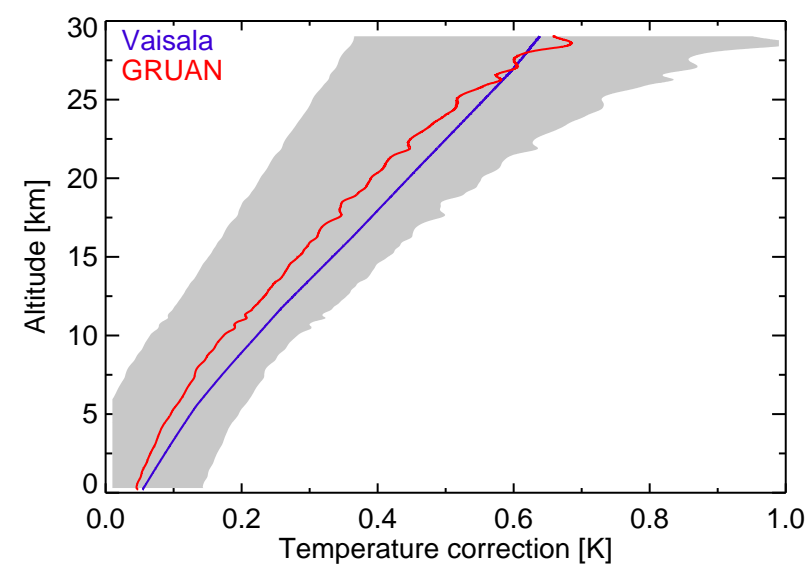

Figure 7. Comparison of the GRUAN and Vaisala correction models for the radiation temperature error. Blue trace: Vaisala correction profile (DigiCora version 3.64); red trace: GRUAN correction profile. The grey bar represents the uncertainty estimate of the GRUAN temperature correction. The correction profiles are evaluated for a sounding performed at Lindenberg on 17 September 2013 at 12:00 UTC; maximum solar zenith angle during the sounding: $36.5^{\circ}$.

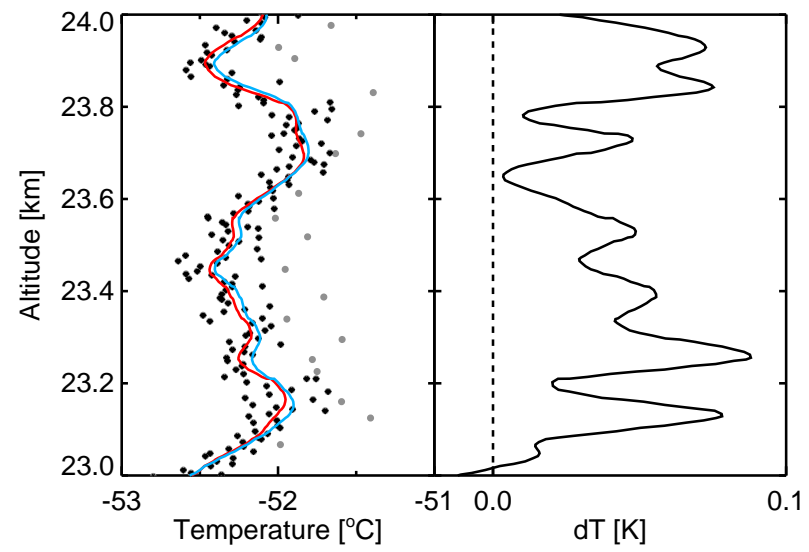

Figure 8. Left panel: temperature profile before (black dots) and after smoothing and consecutive spike removal (red trace). The grey dots represent the temperature spikes that were removed by the spike-removal algorithm. The blue trace represent the smoothed profile before spike removal. The right panel shows the difference between the blue and the red curves. The sounding was performed in Lindenberg on 16 August 2012 (12:00 UTC); maximum solar zenith angle during the sounding: $48.9^{\circ}$.

sensor is close to equilibrium with the surrounding air, so it is unlikely to affect the temperature measurement. However, after exiting the cloud, condensate starts to evaporate, leading to evaporative cooling of the sensor until all water or ice has evaporated. The magnitude and vertical extent of the error due to evaporative cooling are difficult to quantify as they depend on the unknown amount and phase of the condensate deposited on the sensor, and on the temperature and humidity of the ambient air above the cloud.

Vaisala uses a special hydrophobic coating for the temperature sensor and the sensor boom to make the RS92 less prone to evaporative cooling. Currently, the GRUAN processing does not correct for this effect. In the next version of the data processing, evaporative cooling will be detected by superadiabatic lapse rates that coincide with a rapid decrease of humidity away from (near) saturation. The uncertainty budget will be adjusted where these SLRs occur.

\subsection{Sensor time-lag}

The RS92 temperature sensors respond to changes in the ambient temperature, with typical time constants of $1.7 \mathrm{~s}$ at $3 \mathrm{hPa}, 1.3 \mathrm{~s}$ at $10 \mathrm{hPa}$, and $<0.5 \mathrm{~s}$ below $100 \mathrm{hPa}$ (Vaisala, 2007). Sensors made prior to 2007 were slightly thinner and responded with time constants approximately $60 \%$ smaller (e.g. $1 \mathrm{~s}$ at $3 \mathrm{hPa}$ ). The response of the temperature sensor converges exponentially to changes in ambient temperature, and the time constant is the time needed to register $63 \%$ of a step change in temperature. These response times are fast enough to keep the temperature error due to sensor time-lag below $0.1 \mathrm{~K}$. Therefore, no correction for time-lag of the temperature sensor is applied in the GRUAN product.

\subsection{Uncertainty budget}

The contributing uncertainties, together with their attributed values and their classification as correlated or uncorrelated, are listed in Table 2. First, an important correlated uncertainty is the accuracy of the calibration, which is composed of calibration uncertainty $u_{\mathrm{c}}=0.15 \mathrm{~K}(2 \sigma, k=2)$ given by Vaisala (2007) and the temperature difference during ground check $\Delta T_{\mathrm{GC} 25}$.

$u_{\mathrm{c}, \text { absolute }}(\mathrm{cal})=\sqrt{u_{\mathrm{c}}^{2}+\left(\Delta T_{\mathrm{GC} 25} / 3\right)^{2}}$

The factor of 3 is according to Sect. 4.4.5 of JCGM/WG 1 (2008). The uncorrelated uncertainty of the temperature is given by the statistical uncertainty, determined by the spikeremoval algorithm (Sect. 5.3). Currently, the data field for the uncorrelated uncertainty in the product file (u_std_temp) contains the standard deviation instead of the statistical uncertainty. The latter can be calculated by dividing by $\sqrt{N^{\prime}}$, with $N^{\prime}=11$ being the effective sample size of the kernel of the smoothing filter (Eq. A4).

The uncertainty of the radiation correction is comprised of three main sources of uncertainty: the actinic flux $I_{\mathrm{a}}$, which is assumed to be the average of the cloudy and cloud-free case (Sect. 5.2.2); the radiation temperature error correction model; and the ventilation speed $v$.

Here the uncertainty in $I_{\mathrm{a}}$ is a combination of the unknown orientation of the temperature sensor with respect to the Sun and the uncertainty in the albedo (Eq. 3). The uncertainty of 
Table 2. Overview of the sources contributing to the temperature uncertainty budget; values are given for $2 \sigma(k=2)$. The items involving $\Delta T$ relate to the radiation temperature correction.

\begin{tabular}{|c|c|c|c|}
\hline Parameter & Value & (Un)correlated & Data field in product \\
\hline Repeatability of calibration of the $T$ sensor $u_{\mathrm{c}}(\mathrm{cal})$ & $0.15 \mathrm{~K}$ & correlated & \\
\hline $\begin{array}{l}\text { Absolute uncertainty of } T \text { sensor calibration } \\
u_{\mathrm{c}, \mathrm{cal}}(T)\end{array}$ & $\sqrt{u_{\mathrm{c}}(\mathrm{cal})^{2}+\left(\Delta T_{\mathrm{GC} 25 / 3)^{2}}\right.}$ & correlated & u_cor_temp* \\
\hline Uncertainty in $T$ due to spike removal & $0.05 \mathrm{~K}$ & correlated & \\
\hline Uncertainty in $T$ due to sensor time-lag & $<0.03 \mathrm{~K}$ & correlated & \\
\hline$\sigma(T)$ & Statistical standard deviation & uncorrelated & u_std_temp* \\
\hline Random uncertainty of temperature $u_{\mathrm{u}}(T)$ & $\begin{array}{l}\text { Statistical uncertainty } \\
\sigma(T) / \sqrt{N^{\prime}}\end{array}$ & uncorrelated & \\
\hline $\begin{array}{l}\text { Uncertainty of } \Delta T \text { due to rotating radiosonde } \\
u_{\mathrm{u}, \operatorname{rot}}(\Delta T)\end{array}$ & $2 \cdot \Delta T / \sqrt{3}$ & uncorrelated & \\
\hline Uncertainty of $I_{\mathrm{a}}$ due to albedo $u_{\mathrm{c}}\left(I_{\mathrm{a}}\right)$ & $\frac{1}{2 \cdot \sqrt{3}}\left|I_{\mathrm{a}}^{\text {clear sky }}-I_{\mathrm{a}}^{\text {cloudy }}\right|$ & correlated & u_swrad* \\
\hline $\begin{array}{l}\text { Uncertainty in } \Delta T \text { due to uncertainty in albedo } \\
u_{\mathrm{c}, I_{\mathrm{a}}}(\Delta T)\end{array}$ & $\Delta T \cdot u_{\mathrm{c}}\left(I_{\mathrm{a}}\right) / I_{\mathrm{a}}$ & correlated & \\
\hline Uncertainty in ventilation velocity $u(v)$ & $1 \mathrm{~ms}^{-1}$ & uncorrelated & \\
\hline $\begin{array}{l}\text { Uncertainty in } \Delta T \text { due to ventilation uncertainty } \\
u_{u} \text {. }\end{array}$ & $\Delta T \cdot u(v) / v$ & uncorrelated & \\
\hline $\begin{array}{l}\text { Uncertainty in } \Delta T \text { due to uncertainty in parameters } \\
a \text { and } b u_{\mathrm{c}, \mathrm{RC}}(\Delta T)\end{array}$ & $<0.2 \mathrm{~K}$ & correlated & \\
\hline Total uncertainty & $\begin{array}{l}{\left[u_{\mathrm{c}, \operatorname{cal}}(T)^{2}+u_{\mathrm{u}}(T)^{2}+\right.} \\
u_{\mathrm{u}, \operatorname{rot}}(\Delta T)^{2}+u_{\mathrm{c}, I_{\mathrm{a}}}(\Delta T)^{2}+ \\
\left.u_{\mathrm{u}, \operatorname{vent}}(\Delta T)^{2}+u_{\mathrm{c}, \mathrm{RC}}(\Delta T)^{2}\right]^{1 / 2}\end{array}$ & - & u_temp* \\
\hline
\end{tabular}

\footnotetext{
* In the product file for processing version 2 the uncertainty is stored as $k=1$.
}

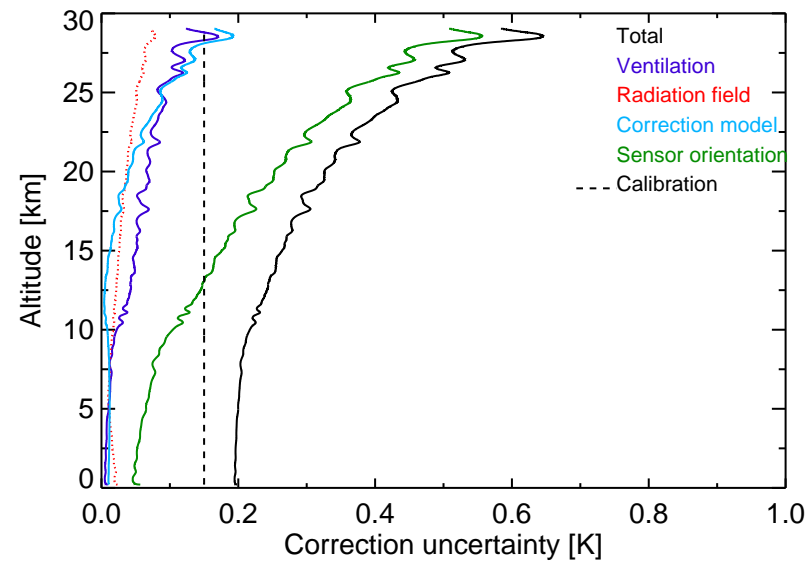

Figure 9. Contributions of the various uncertainty terms to the total uncertainty estimate of the GRUAN temperature correction for a sounding performed in Lindenberg on 17 September 2013 at 12:00 UTC; maximum solar zenith angle during the sounding: $36.5^{\circ}$. The radiation field represents the uncertainty due to the unknown albedo of the cloudy/cloud-free scene.

the correction model reflects the uncertainty in the parameters $a$ and $b$ in Eq. (1). The total uncertainty in the temperature correction is the geometric sum of the squared individual uncertainties.
Total uncertainty in Fig. 9 increases progressively with altitude, a result of the fact that the radiation correction and its associated uncertainty increases with decreasing pressure. Up to approximately $15 \mathrm{~km}$ the total uncertainty is dominated by the sensor calibration, but above this altitude the dominant source of uncertainty is the sensor orientation, together with the correction parameters $a$ and $b$, and the uncertainty of the ventilation speed. The grey shaded area in Fig. 7 shows the uncertainty of the radiation correction vertically resolved.

As shown in Fig. 9, around $25 \mathrm{~km}$ altitude the main factors of the uncertainty of the radiation correction are sensor orientation $(0.4 \mathrm{~K})$, ventilation speed $(0.1 \mathrm{~K})$, correction model $(0.1 \mathrm{~K})$, and albedo $(0.05 \mathrm{~K})$.

The uncertainty associated with the uncorrected error due to the time-lag of the temperature sensor (Sect. 5.5) is estimated to be less than $0.03 \mathrm{~K}$. The uncertainty associated with smoothing and spike removal (Sect. 5.3) is estimated at $0.05 \mathrm{~K}$.

The uncertainty sources that are classified as correlated in Table 2 are correlated in the vertical, but not all of these uncertainties are correlated over a time series because the associated errors do not occur at the same altitude in each sounding. The error due to sensor time-lag depends on the altitudes of temperature inversions, which vary from sounding to sounding. For daytime soundings the radiation-induced temperature error above the tropopause mainly depends on am- 

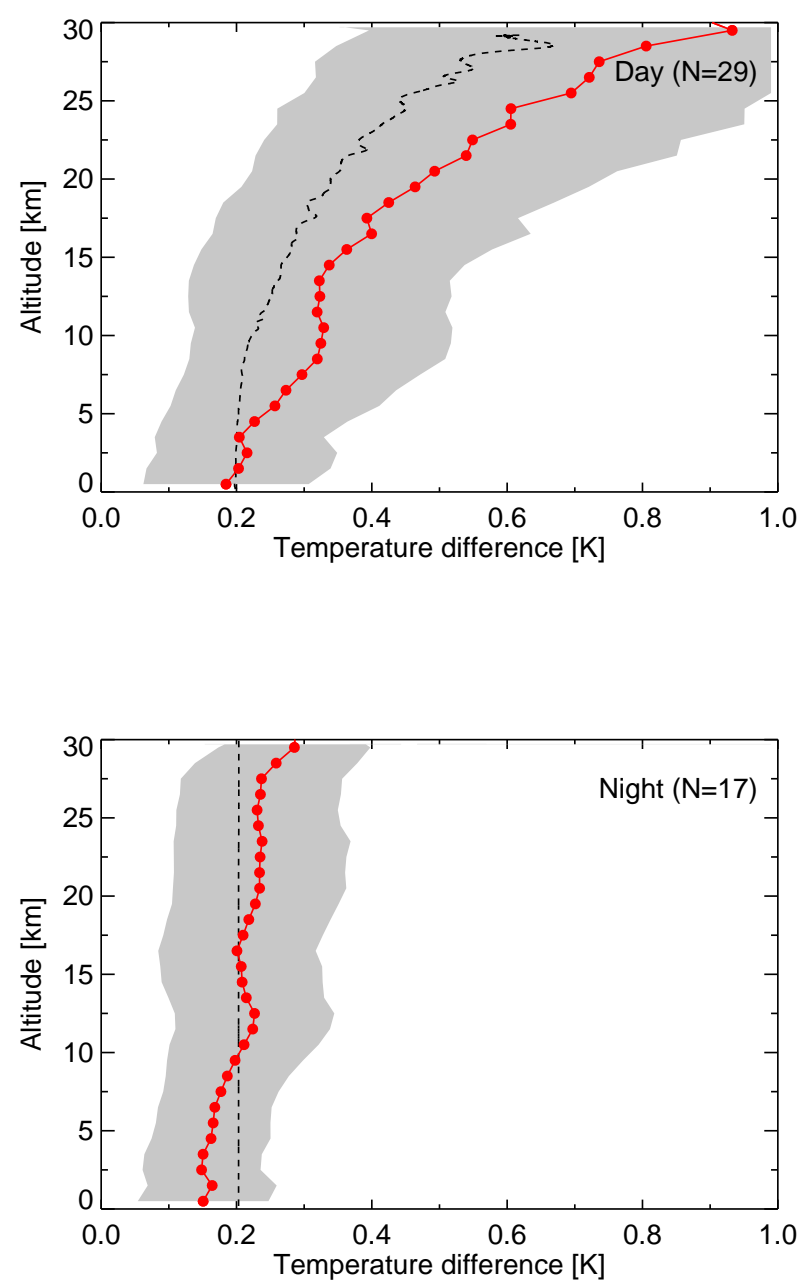

Figure 10. Uncertainty of the temperature measurements, determined from 29 noon (top) and 17 midnight (bottom) RS92 dual launches performed in Lindenberg. The red line represents the mean of the difference of GRUAN temperature profiles; the black trace denotes the estimated uncertainty profile calculated for soundings performed on 17 September 2013; both traces are given for $k=2$. The grey band represents the standard deviation of the measured temperature differences. Data are gridded in $1 \mathrm{~km}$ wide bins. The maximum solar zenith angle during the noon sounding was $36.5^{\circ}$.

bient pressure and therefore leads to correlated uncertainties in time series.

\subsubsection{Other error sources}

The payload configuration may introduce an additional error source. If a radiosonde is attached to a white styrofoam ozone sonde box, this can act as a scattering surface and enhance the actinic flux on the temperature sensor in the same manner as clouds. A large object close to the radiosonde may also obstruct the proper ventilation of the temperature sensor. The GRUAN product does not employ a correction algorithm for the radiation and ventilation errors related to payload con-

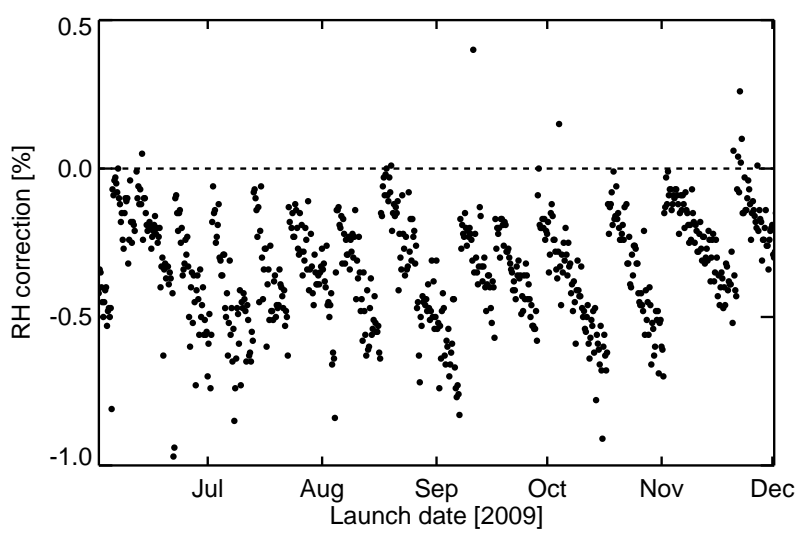

Figure 11. RH-sensor recalibration during ground check in the GC25 for RS92 radiosondes launched at Lindenberg in the second half of 2009. The desiccant is replaced bi-weekly, or when the recalibration exceeds $1 \% \mathrm{RH}$.

figuration. These errors are hard to quantify, and systematic experimental data to create such a correction on is lacking. Therefore, in addition to the recommendations on the exposure of the temperature sensor given in chapter 12 of WMO (2008), proper separation between neighbouring instruments within a payload should be considered, not only to ensure proper ventilation but also to minimize the additional radiation error. Another effect of large payloads is the change of the rotation frequency of the rig, which changes the size and shape of the temperature spikes (Sect. 5.3). The GRUAN spike algorithm removes all temperature spikes that exceed the threshold, provided the spike duration is short enough to be detected by the low-pass filter.

\subsection{Verification}

At Lindenberg multiple soundings were performed with two RS92 radiosondes attached to the same balloon. Usually, these dual soundings were part of a larger scientific payload for which various configurations were used. These dual soundings are very useful for verification of the uncertainty of the GRUAN product. The flights were screened to ensure that the RS92 sondes were not located too close to the other instruments, which could lead to atypical temperature errors due to reflected radiation.

Figure 10 compares the measured uncertainty, i.e. the mean of the absolute temperature differences between the two RS92 sondes, and the GRUAN estimated uncertainties. The difference between the modelled and the measured uncertainty increases with altitude to approximately $0.15 \mathrm{~K}$ at $30 \mathrm{~km}$. This underestimation of the modelled uncertainty implies that the random part of the radiation temperature error may not be fully characterized and described by the correction model. It may also imply that an unknown error source has been overlooked. The night-time measurements show good agreement between the modelled uncertainty and 
the observed mean difference. Here the modelled uncertainty solely consists of the reported Vaisala calibration uncertainty.

It is important to realize that this comparison of dual launches only reveals random errors and systematic biases that differ among individual sondes. Systematic biases that may affect all RS92 radiosondes equally can be detected by comparing dual soundings of different types of radiosondes, or by comparing to temperature profile data from other measurement systems.

\section{Humidity}

\subsection{Introduction}

The Humicap consists of a hydro-active polymer thin film as dielectric between two electrodes applied on a glass substrate (Salasmaa and Kostamo, 1975; Smit et al., 2013). The humidity sensors are not covered by protective caps, but they are alternately heated to prevent icing. To prevent overheating, the heating of the humidity sensors is switched off below $-60^{\circ} \mathrm{C}$, or above $100 \mathrm{hPa}$, whichever is reached first. Humicaps show good performance over a wide range of temperatures but suffer from systematic errors such as dry bias due to solar radiative heating and a response lag below $-40^{\circ} \mathrm{C}$.

Calibration of the Humicap sensors is performed in Vaisala's CAL4 calibration facility, at humidity conditions ranging from 0 to $90 \%$, using SI traceable dew point meters and with an accuracy of $1 \%$ RH (Vaisala, 2002).

Three main error sources are known to affect the humidity profile:

- daytime solar heating of the Humicaps introduces a dry bias,

- sensor time-lag at temperatures below about $-40^{\circ} \mathrm{C}$,

- temperature-dependent calibration correction.

The GRUAN corrections for these errors will be discussed in the following sections. Following the historical convention used in meteorology, the humidity is given in percent RH over liquid water, even for temperatures well below 0 where this quantity has little physical meaning. Appendix A of Miloshevich et al. (2006) provides a thorough discussion on the use of saturation pressure over water and over ice. It is essential that when comparing humidity data from different processing sources the same saturation vapour pressure formulations are used. Both the Vaisala and GRUAN processing employ the formulation by Hyland and Wexler (1983).

\subsection{Pre-launch preparation}

During the pre-launch ground check procedure, the readings of the humidity sensors over a desiccant in a near $0 \% \mathrm{RH}$

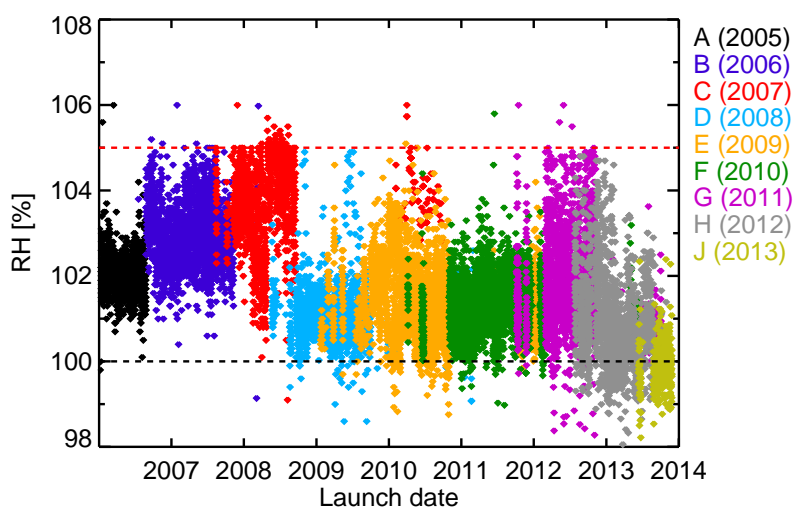

Figure 12. Time series of reading of the RS92 humidity sensor when inserted in the SHC (100\% relative humidity) prior to launch, as part of the additional manufacturer-independent ground check. The colours depict the radiosonde's production year. The black dashed line represents the $100 \%$ level, whereas the red dashed line indicates $105 \%$, the rejection criterion for humidity readings in the SHC.

environment are used to determine potential drifts in the calibration of the sensors. The Vaisala DigiCora software subtracts these values from the measured profile, under the assumption that the desiccant achieves a $0 \% \mathrm{RH}$ environment. At Lindenberg we observed that the RH correction during ground check usually is less than $0.1 \% \mathrm{RH}$ shortly after replacement of the desiccant and over time gradually increases to at most $1 \% \mathrm{RH}$ before it is replaced again, as is illustrated in Fig. 11. This indicates that the RS92 humidity sensor is able to measure the degradation of the desiccant, which implies that the assumption of $0 \% \mathrm{RH}$ over the desiccant is not valid, and this reading should not be used for recalibration of the humidity sensor. The recalibration of the RH sensors with the ground check readings will in fact introduce a systematic bias in the entire humidity profile, especially at tropical sites where high ambient humidity will quickly degrade the desiccant. Therefore, we recommend exchanging the desiccant when the ground check correction exceeds $1 \% \mathrm{RH}$. The Vaisala GC25 recalibration of the humidity sensors is not applied in the GRUAN processing but is used in the quality control (Sect. 4) and is added to the uncertainty estimate.

\subsection{Additional ground check in Standard Humidity Chamber}

When an additional, manufacturer-independent, ground check is available, these readings are also used in the uncertainty budget and as a quality criterion.

Since 2006 all RS92s at Lindenberg observatory are routinely checked using an SHC prior to launch. The SHC is a cylindrical vessel which contains saturated air (100\% RH) above a few centimetres of distilled water. Supersaturation is not expected due to the presence of condensation nuclei in the ambient air; this is supported by the observation that 


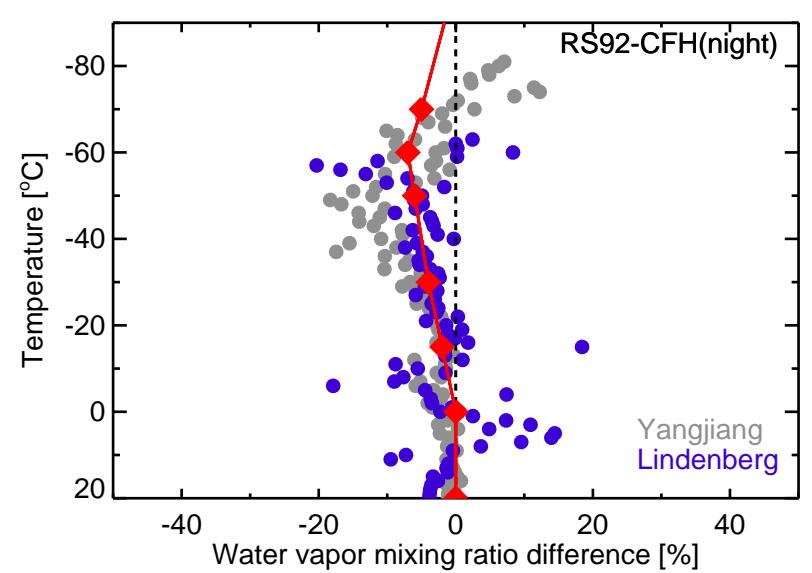

Figure 13. Comparison of night-time humidity profiles from RS92 and coincident cryogenic frost point hygrometer (CFH) data taken in 2010 in Lindenberg (blue) and Yangjiang (grey). The RS92 data were corrected for radiation dry bias and time-lag using the GRUAN correction algorithms. The red squares represent the temperaturedependent calibration correction that is derived from these data.

droplets are formed at the walls of the SHC. The measurement in the SHC is used for traceability, to track instrument changes, and as a quality check of the radiosonde. Figure 12 shows that between 2006 and 2013 the bias of the RS92's humidity sensor in saturated air changed by almost $4 \% \mathrm{RH}$. At Lindenberg a radiosonde is not used if it shows a bias of more than $5 \%$ RH.

We strongly recommend the additional ground check of radiosondes in an SHC for GRUAN measurements. Currently, the SHC is in use at several GRUAN stations, and analysis of the SHC measurements showed that at one station the reconditioning of the RS92 was systematically skipped, which led to a $1-5 \%$ RH dry bias.

Currently, the humidity readings in the SHC only add to the uncertainty estimate. In the absence of an additional ground check, $2.5 \% \mathrm{RH}$ is added to the calibration uncertainty. A future version of the data product may use SHC results to correct the measured humidity profile. One of the criteria for implementing this SHC-based correction in the GRUAN processing is a universal use of the SHC within the GRUAN network, which currently is not fulfilled yet.

\subsection{Calibration correction}

As result of the Atmospheric Infrared Sounder (AIRS) Water Vapor Experiment (AWEX) campaign, Miloshevich et al. (2006) reported a temperature-dependent bias in night-time RS92 humidity data that can not be attributed to radiative heating or time-lag of the humidity sensor. Using comparison with data from the cryogenic frost point hygrometer $(\mathrm{CFH})$, Vömel et al. (2007b) estimated that this dry bias can be as large as $9 \%$ of the measured humidity. This dry bias predominantly occurs between -40 and $-60^{\circ} \mathrm{C}$, with a peak

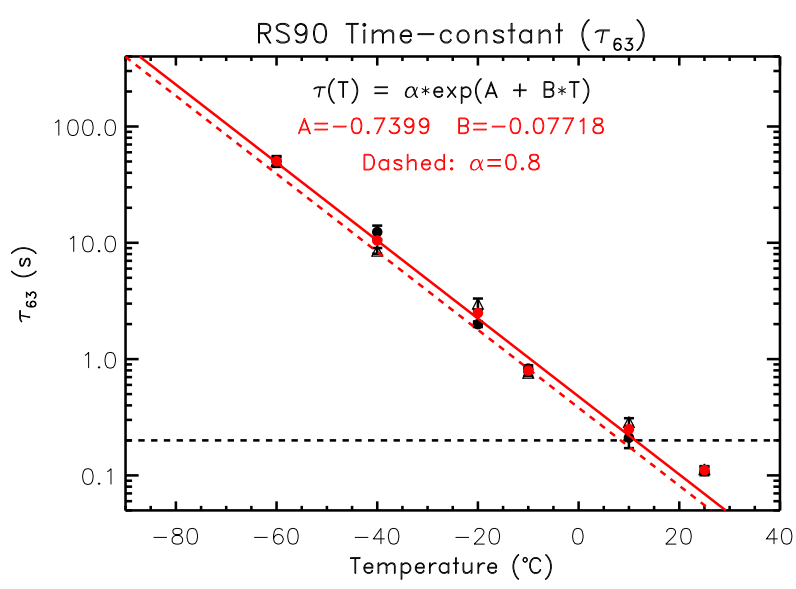

Figure 14. RS90 and RS92 RH sensor time constant as a function of temperature from Vaisala laboratory measurements. The black data points are the same as in Fig. 2 of Miloshevich et al. (2004), where the circles and triangles represent the mean time constants for increasing $\mathrm{RH}$ and decreasing $\mathrm{RH}$, respectively. The red symbols are the average of the time-constant values for increasing and decreasing RH. The exponential fit is based on the average of the timeconstant values for increasing and decreasing $\mathrm{RH}$ (red circles). The data point at $+25^{\circ} \mathrm{C}$ is not used in the fit. The scale factor $\alpha=0.8$ (dashed line) corresponds to about 2 standard deviations below the mean, meaning that $95 \%$ of sensors will be slightly under-corrected and $5 \%$ will be overcorrected (i.e. a conservative approach). The plot was provided by L. Miloshevich.

at approximately $-50^{\circ} \mathrm{C}$. There is no physical mechanism to account for the temperature-dependent dry bias, and it is attributed to inaccuracies in the Vaisala calibration of the humidity sensors (Miloshevich et al., 2006). The GRUAN processing corrects this dry bias by multiplying with an empirical correction factor which follows from linear interpolation between the reference points given in Table 3. Figure 13 shows the CFH-RS92 comparisons performed at Lindenberg and Yangjiang that were used to derive the correction factor. The bias that occurs between -20 and $-70^{\circ} \mathrm{C}$ is attributed to the temperature-dependent dry bias, and the value of the correction factor is chosen to minimize this bias.

The values in Table 3 are similar to the values given by Vömel et al. (2007b). Regular comparisons with coincident frost point hygrometer data are necessary to validate the calibration correction because changes in the Vaisala calibration of the humidity sensors directly affect the accuracy of the calibration correction. The calibration correction is applied prior to the corrections for the radiation dry bias and the time-lag.

\subsection{Radiation dry bias}

Solar radiation heats the humidity sensors and introduces a dry bias, because inside the warm sensor the relative humidity is lower. Similar to the radiation error of the tempera- 
Table 3. Parameters for the temperature-dependent calibration correction of humidity values. The first row lists the correction factor, and the second row the uncertainty of the correction.

\begin{tabular}{lrrrrrrrr}
\hline Temperature $\left[{ }^{\circ} \mathrm{C}\right]$ & 20 & 0 & -15 & -30 & -50 & -60 & -70 & -100 \\
Correction factor & 1 & 1 & 1.02 & 1.04 & 1.06 & 1.07 & 1.05 & 1 \\
Uncertainty & 0.01 & 0.02 & 0.03 & 0.03 & 0.06 & 0.07 & 0.05 & 0.10 \\
\hline
\end{tabular}

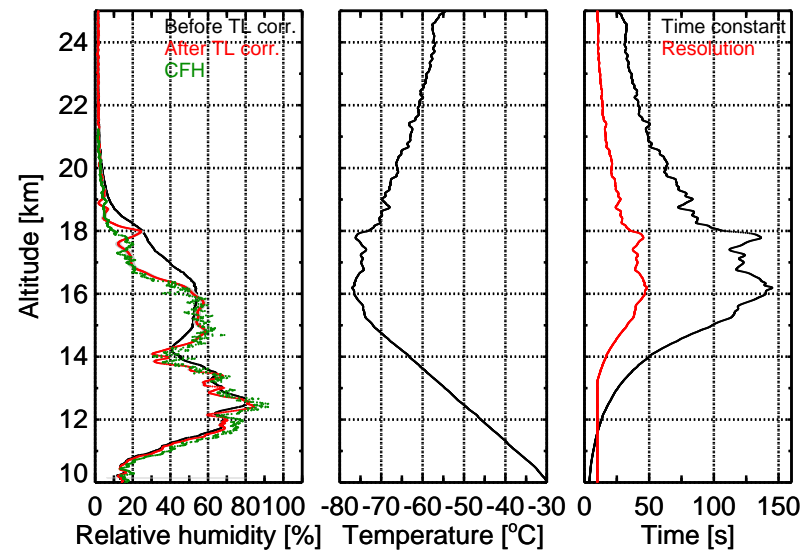

Figure 15. Effect of time-lag on the RS92 humidity profile. Left panel: comparison of RS92 humidity profile before (black) and after (red) GRUAN time-lag correction, and coincident $\mathrm{CFH}$ profile (green). Middle panel: temperature profile from RS92. Right panel: the time-lag constant $\tau$ (black) and the time resolution of the humidity profile after the filtering by the time-lag correction algorithm (red). The sounding was performed in Yangjiang on 20 July 2010.

ture sensor, the dry bias increases with altitude. The relative error due to the radiation dry bias can range from $9 \%$ at the surface to $50 \%$ at $15 \mathrm{~km}$ (Vömel et al., 2007b; Miloshevich et al., 2009). The same approach as for the temperature is used to estimate the heating of the humidity sensor as a function of flux, pressure, and ventilation speed. The measured profile $\mathrm{RH}_{\mathrm{m}}$ is multiplied with a correction factor, derived from the ratio of the saturation vapour pressure $p_{\mathrm{s}}$ over water in the heated sensor and in the ambient air:

$\mathrm{RH}_{\mathrm{c}}=\mathrm{RH}_{\mathrm{m}} \frac{p_{\mathrm{s}}(T+f \Delta T)}{p_{\mathrm{s}}(T)}$,

where $\mathrm{RH}_{\mathrm{c}}$ denotes the corrected humidity, $T+f \Delta T$ represents the (estimated) temperature of the humidity sensor, and $p_{\mathrm{s}}$ is calculated according to Hyland and Wexler (1983). $\Delta T$ is the radiative heating of the temperature sensor calculated from the estimated actinic flux $I_{\mathrm{a}}$, using Eq. (1), and $f$ is an empirical scale factor that accounts for the higher sensitivity of the humidity sensors to radiative heating than the temperature sensor. From the comparison of daytime $\mathrm{RH}$ profiles from RS92 and CFH reported by Vömel et al. (2007b) it is estimated that the Humicap's sensitivity to solar heating is approximately $13( \pm 3)$ times that of the temperature sensor.

In 2006 Vaisala modified the coating on the underside of the sensor boom, and in 2009 a reflective coating was applied
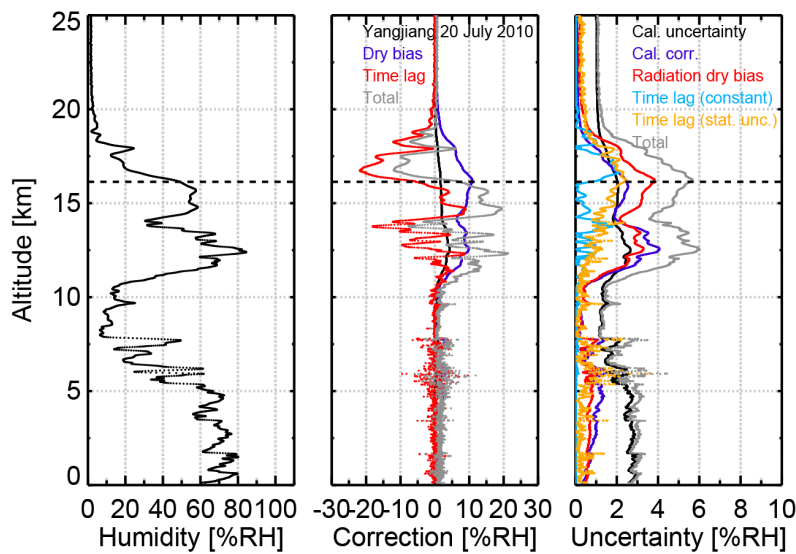

Figure 16. Corrections and their estimated uncertainties to the relative humidity. Left panel: humidity profile. Middle panel: profiles of the corrections for the temperature-dependent calibration correction (black), radiation dry bias (blue), and time-lag (red). The grey trace represents the total correction. Right panel: estimates of the total uncertainty (grey) and the various contributions due to the correction for calibration uncertainty (black), the correction for the temperature-dependent calibration correction (blue), radiation dry bias (red), time-lag constant $u(\tau)$ (light blue), and the statistical uncertainty of the time-lag correction (orange). The horizontal dashed line at $16.1 \mathrm{~km}$ represents the tropopause.

Table 4. Estimated sensitivity of the humidity sensor to radiative heating, relative to the temperature sensor. The estimated radiative heating of the temperature sensor, multiplied with the sensitivity factor $f$, yields the radiative heating of the RS92 humidity sensor. The sensitivity factor depends on production year, the right-most column represents the uncertainty in $f$.

\begin{tabular}{lrr}
\hline Production year & Sensitivity factor $f$ & $u(f)$ \\
\hline$<2006$ & 13 & 4 \\
2006-2008 & 10 & 3 \\
2009-present & 6.5 & 2 \\
\hline
\end{tabular}

to the contacts of the humidity sensors (Vaisala continuity website, 2013). The corresponding batch numbers for these production changes are given at Vaisala continuity website (2013). Both changes reduced the radiation sensitivity of the humidity sensors. This is shown in Table 4, which lists the value of $f$ for various production years, based on radiation tests performed at Lindenberg. For the currently produced RS92 radiosondes a value of 6.5 is used for $f$. 


\subsection{Time-lag correction}

The response of polymer humidity sensors slows with decreasing temperature, ranging from less than $1 \mathrm{~s}$ at $+20^{\circ} \mathrm{C}$ to several minutes at $-80^{\circ} \mathrm{C}$. This results in flattening and smoothing of gradients and any structure in the humidity profile at colder temperatures. Time-lag of the RS92 humidity sensors starts to be significant at $-40^{\circ} \mathrm{C}$, where the response time is approximately $20 \mathrm{~s}$, which decreases the vertical resolution of the measured humidity profile to more than $100 \mathrm{~m}$. The time-lag introduces correlated errors in the upper troposphere and tropopause region, and strongly affects the reliability of stratospheric profiles.

Miloshevich et al. (2004) present tables of the humidity sensor's time constant between -60 and $+25^{\circ} \mathrm{C}$ that were determined in laboratory experiments performed by Vaisala. In the same paper, a correction algorithm for the time-lag is proposed that is based on the numerical solution of the exponential growth-law equation (Eqs. 2-4 by Miloshevich et al., 2004). In the GRUAN correction algorithm, which is inspired by Miloshevich et al. (2004), the time-lag is represented by a low-pass filter with an exponential kernel:

$\mathrm{RH}_{i}^{\mathrm{m}}=\frac{\sum_{j=0}^{i} \mathrm{RH}_{j}^{\mathrm{a}} \exp \left(\frac{t_{j}-t_{i}}{\tau_{i}}\right)}{\sum_{j=0}^{i} \exp \left(\frac{t_{j}-t_{i}}{\tau_{i}}\right)}$,

with $\mathrm{RH}^{\mathrm{m}}$ being the measured humidity, $\mathrm{RH}^{\mathrm{a}}$ the true ambient humidity, $\tau$ the temperature-dependent time constant, and time $t$. The time-lag-corrected ambient humidity $\mathrm{RH}_{i}^{\mathrm{a}^{*}}$ follows from inverting Eq. (6),

$\mathrm{RH}_{i}^{\mathrm{a}^{*}}=\mathrm{RH}_{i}^{\mathrm{m}}+\sum_{j=0}^{i-1}\left(\mathrm{RH}_{i}^{\mathrm{m}}-R H_{j}^{\mathrm{a}^{*}}\right) \exp \left(\frac{t_{j}-t_{i}}{\tau_{i}}\right)$.

The relation between time constant $\tau$ and temperature $T$ $\left({ }^{\circ} \mathrm{C}\right)$ is approximated by

$\tau=A \cdot \exp \left(c_{0}+c_{1} \cdot T\right)$,

with the parameters $A=0.8, \quad c_{0}=-0.7399$, and $c_{1}=$ -0.07718 as shown in Fig. 14. It is assumed that the time constant is the same for increasing and decreasing humidity, and the uncertainty in $\tau$ is estimated by

$u(\tau)=0.5 \cdot \tau(1-A)$.

The numeric inversion by Eq. (7) amplifies both real effects and noise. The noise is removed by a low-pass digital filter, and its impact on the uncertainty is added to the uncertainty budget. The cut-off frequency $f_{\mathrm{c}}$ of the low-pass filter is inversely proportional to the time-lag constant.

$f_{\mathrm{c}}=\frac{3}{\tau} \quad$ and $f_{\mathrm{c}}<0.1 \mathrm{~Hz}$
The factor of 3 prevents the removal of genuine structures in the time-lag-corrected humidity profile when $\tau$ is large. Using a higher cut-off frequency (i.e. using a factor larger than 3 ) would enhance the structures and increase the temporal resolution of the humidity profile, at the cost of increasing the noise of the profile as well. An important consequence of applying the low-pass filter is that it decreases the temporal resolution of the humidity profile to $10 \mathrm{~s}$ or more, depending on the value of $\tau$.

Figure 15 illustrates the impact of time-lag at temperatures below $-50{ }^{\circ} \mathrm{C}$. A tropical sounding is displayed because the low temperatures in tropopause region cause a strong time-lag effect. In comparison with a coincident $\mathrm{CFH}$ sounding, the uncorrected RS92 humidity profile above $12.5 \mathrm{~km}$ is smoother, and structures that are still resolved by the CFH begin to disappear. The left panel of Fig. 15 also shows how the time-lag correction restores these structures, and the corrected humidity profile shows good agreement with the $\mathrm{CFH}$ profile.

\subsection{Uncertainty estimates}

An overview of the various sources that contribute to the uncertainty budget of the humidity profile is given in Table 5 and shown in Fig. 16.

\subsubsection{Instrument calibration}

The calibration uncertainty is a correlated uncertainty which applies to the entire profile. It consists of an absolute and a relative part, and it is determined from the uncertainty specified by Vaisala and from the sensor readings in the $\mathrm{GC} 25$ and the SHC (if available). The GC25 RH reading, although not applied to the correction, contributes to the calibration

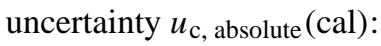

$u_{\mathrm{c}, \text { absolute }}(\mathrm{cal})=$
$\sqrt{u_{\mathrm{c}}^{2}+\left(\Delta U_{1} / 3\right)^{2}+\left(\Delta U_{2} / 3\right)^{2}+\left(U_{1}-U_{2}\right)_{\mathrm{GC} 25}^{2}+\left(U_{1}-U_{2}\right)_{\mathrm{SHC}}^{2}}$.

Here $u_{\mathrm{c}}$ denotes the Vaisala-specified calibration uncertainty of $1 \% \mathrm{RH}$ at $k=2,\left(U_{1}-U_{2}\right)_{\mathrm{GC} 25}$ the difference between the humidity sensors during ground check, and $\left(U_{1}-U_{2}\right)_{\mathrm{SHC}}$ the difference between the humidity sensors in the SHC. $\Delta U_{1}$ and $\Delta U_{2}$ denote the recalibration of humidity sensor $U_{1}$ and $U_{2}$, respectively, and only reflect the quality of the desiccant. Actually, these terms will not be included in the uncertainty budget in the next version of the processing.

The relative calibration uncertainty is set to $2.5 \%$, but if an additional ground check in the SHC is performed it is determined from the sensor readings in the SHC: 

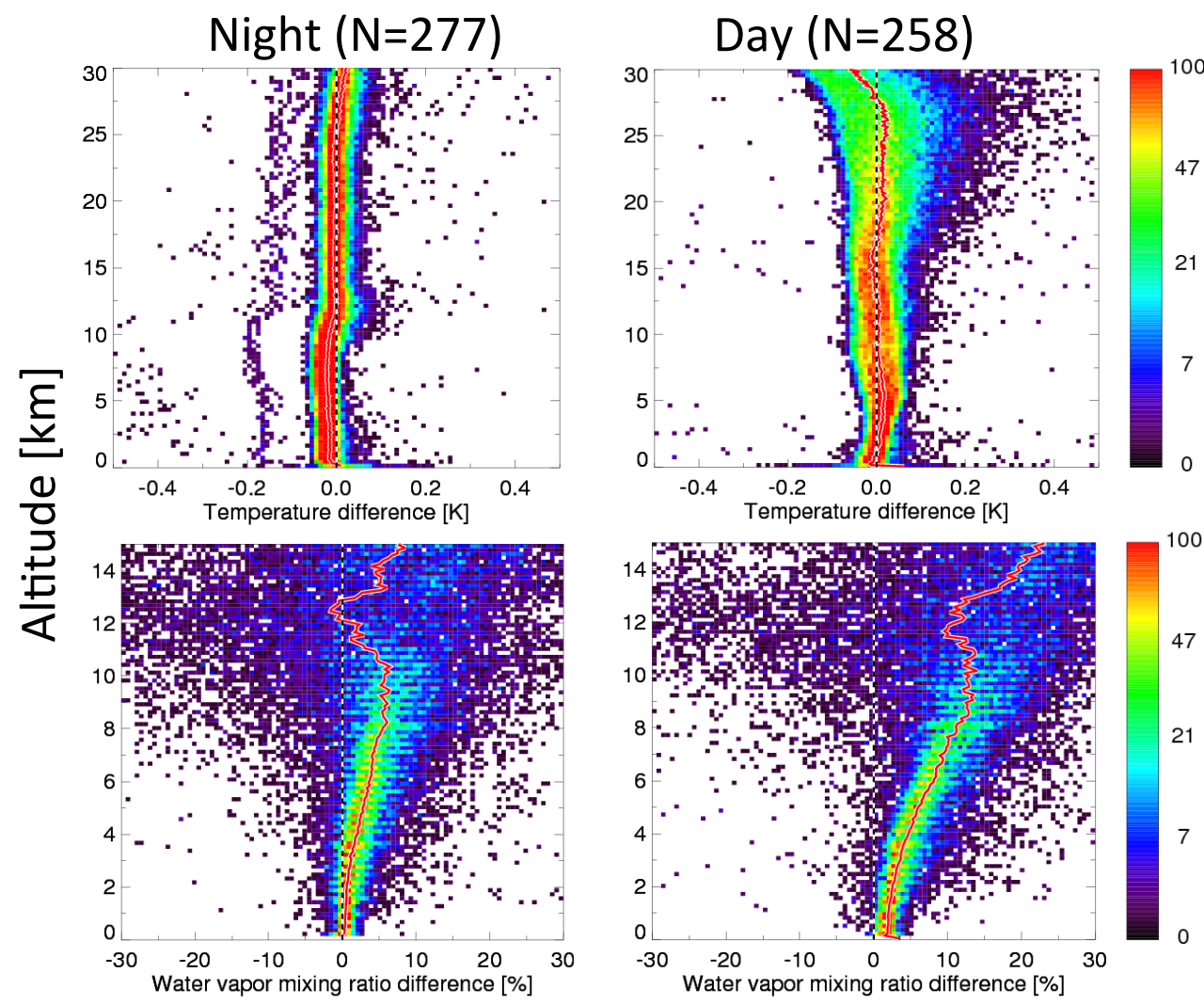

Figure 17. Comparison of GRUAN data processing (GDP) and Vaisala (FLEDT) for RS92 radiosoundings performed in Lindenberg in 2012. The graphs show scatter density plots of $100 \% \times($ GDP - FLEDT)/GDP for temperature (top row) and humidity (bottom row). Data were taken from radiosoundings performed at local midnight (00:00 UTC, left column, $N=277$ ) and local noon (12:00 UTC, right column, $N=258$ ). The GRUAN and Vaisala profile data are gridded in $100 \mathrm{~m}$ wide altitude bins prior to comparison. The logarithmic colour scale represents the number of data points in each bin, and the solid red line represents the average. Bins containing fewer than five data points are excluded from the plot. The tropopause (not indicated) usually resides below $12 \mathrm{~km}$.
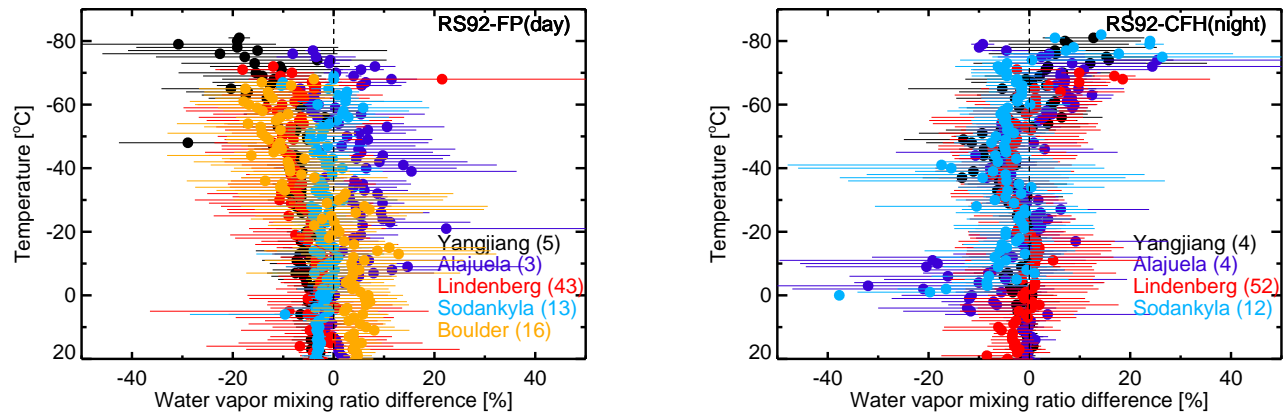

Figure 18. Comparison of humidity profiles from GRUAN-processed RS92 and coincident frost point (FP) hygrometer data. Top: daytime flights; bottom: night-time flights. Data are gridded in $500 \mathrm{~m}$ wide bins and plotted with ambient temperature as the vertical scale. The analysis is restricted to the troposphere. The solid circles represent the relative difference RS92 - FP with respect to the FP humidity, and the bars indicate the statistical uncertainty (standard deviation). All data presented here are for the CFH except for the NOAA FPH data from Boulder; the number of soundings at each site is given in brackets. The approximate water volume mixing ratios at various temperature levels are given in Table 7. 
Table 5. Sources of uncertainty for the humidity profile.

\begin{tabular}{llll}
\hline Parameter & Description & (Un)correlated & Data field in product \\
\hline$u_{\mathrm{c}}(\mathrm{cal})$ & Calibration uncertainty, absolute and relative part. & correlated \\
$u_{\mathrm{c}}(\mathrm{cc})$ & Uncertainty of the temperature-dependent calibration correction & correlated \\
$u_{\mathrm{c}}(\Delta T)$ & Uncertainty of the radiative heating of the $\mathrm{RH}$ sensor & correlated \\
$u_{\mathrm{c}}(\mathrm{RC} T)$ & Uncertainty of dry bias due to $u_{\mathrm{c}}(\Delta T)$ & correlated \\
$u_{\mathrm{c}}(\mathrm{RC})$ & Uncertainty of dry bias due to uncertainty of radiation sensitivity factor & correlated \\
& $f$ & \\
$u_{\mathrm{c}}(\mathrm{RC})$ & Total uncertainty of the dry bias $\sqrt{u_{\mathrm{c}}\left(\mathrm{RC}_{f}\right)^{2}+u_{\mathrm{c}}\left(\mathrm{RC}_{T}\right)^{2}}$ & correlated \\
$u_{\mathrm{c}}(\tau)$ & Uncertainty in time-lag constant & correlated \\
$u_{\mathrm{c}}(\mathrm{TL})$ & Uncertainty in TL correction due to $u_{\mathrm{c}}(\tau)$ & correlated & uncorrelated \\
& Statistical standard deviation of each data point in profile $\mathrm{RH}^{*}$ & uncorrelated & correlated \\
$u_{\mathrm{u}}(\mathrm{RH})$ & Statistical uncertainty of each data point in profile & cor_RH* \\
$u_{\mathrm{c}}(\mathrm{RH})$ & $\sqrt{u_{\mathrm{c}}(\mathrm{cal})^{2}+u_{\mathrm{c}}(\mathrm{cc})^{2}+u_{\mathrm{c}}(\mathrm{TL})^{2}+u_{\mathrm{c}}(\mathrm{RC})^{2}}$ & u_RH* \\
$u(\mathrm{RH})$ & $\sqrt{u_{\mathrm{c}}(\mathrm{RH})^{2}+u_{\mathrm{u}}(\mathrm{RH})^{2}}$ & & \\
\hline
\end{tabular}

* In the product file for version 2 the uncertainty is stored as $k=1$.

Table 6. Overview of RS92-CFH dual soundings used in the comparison.

\begin{tabular}{llllrr}
\hline Site & GRUAN site code & Location & Period & $N_{\text {night }}$ & $N_{\text {day }}$ \\
\hline Alajuela $^{\mathrm{a}}$ & ALA & $10^{\circ} \mathrm{N}, 84^{\circ} \mathrm{W}$ & July 2005, summer 2007 & 4 & 3 \\
Yangjiang & YAN & $21^{\circ} \mathrm{N}, 112^{\circ} \mathrm{E}$ & July 2010 (WMO intercomparison) & 4 & 5 \\
Boulder $^{\mathrm{b}}$ & BOU & $40^{\circ} \mathrm{N}, 105^{\circ} \mathrm{W}$ & 2011 -present & - & 16 \\
Lindenberg & LIN & $53^{\circ} \mathrm{N}, 14^{\circ} \mathrm{E}$ & 2008 -present & 53 & 44 \\
Sodankylä & SOD & $67^{\circ} \mathrm{N}, 26^{\circ} \mathrm{E}$ & 2010 (LAPBIAT) \& 2012-present & 11 & 12 \\
\hline
\end{tabular}

a In the absence of .DC3DB files, the GDP for Alajuela is based on Vaisala EDT data.

${ }^{\mathrm{b}}$ In Boulder the frost point hygrometer (FPH) is employed instead of CFH.

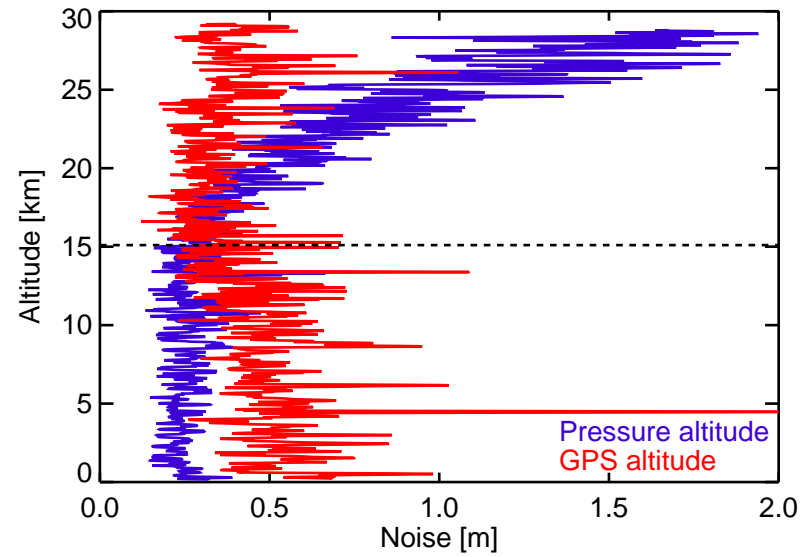

Figure 19. Noise of the geometric altitude derived from the pressure sensor (blue) and the GPS sensor (red). The standard deviation is calculated using Eq. (A5) for a low-pass filter with a cutoff frequency of $0.067 \mathrm{~Hz}$ (corresponding to a period of $15 \mathrm{~s}$ ). The dashed black line indicates the altitude $(15.1 \mathrm{~km})$ where the switch from pressure-based to GPS-based altitude occurs. The sounding was performed at Lindenberg on 17 September 2013 at 12:00 UTC. $u_{\mathrm{c}, \text { relative }}(\mathrm{cal})=$

$\sqrt{\left(U_{1}-U_{\mathrm{SHC}}\right)^{2}+\left(U_{2}-U_{\mathrm{SHC}}\right)^{2}} / U_{\mathrm{SHC}}$,

with $U_{\mathrm{SHC}}=100 \%$. The total calibration uncertainty $u_{\mathrm{c}}$ (cal) is the geometric sum of the absolute and the relative parts and is expressed as

$u_{\mathrm{c}}(\mathrm{cal})=\sqrt{u_{\mathrm{c}, \text { absolute }}(\mathrm{cal})^{2}+u_{\mathrm{c}, \text { relative }}(\mathrm{cal})^{2} \cdot \mathrm{RH}^{2}}$,

with RH being the observed humidity profile. If no ground check is performed, the calibration uncertainty defaults to $4 \%$ RH. The right panel of Fig. 16 shows that the calibration uncertainty (black) is an important contributor to the total uncertainty (grey) of the humidity measurement. It dominates in the lower, warmer, part of the profile where the GRUAN corrections are relatively small, and above the tropopause, where the humidity has dropped to the low levels that prevail in the stratosphere. In the stratosphere the calibration uncertainty of the RS92 is comparable to the relative humidity, which renders the RS92 stratospheric humidity measurements statistically indistinguishable from $0 \% \mathrm{RH}$. 


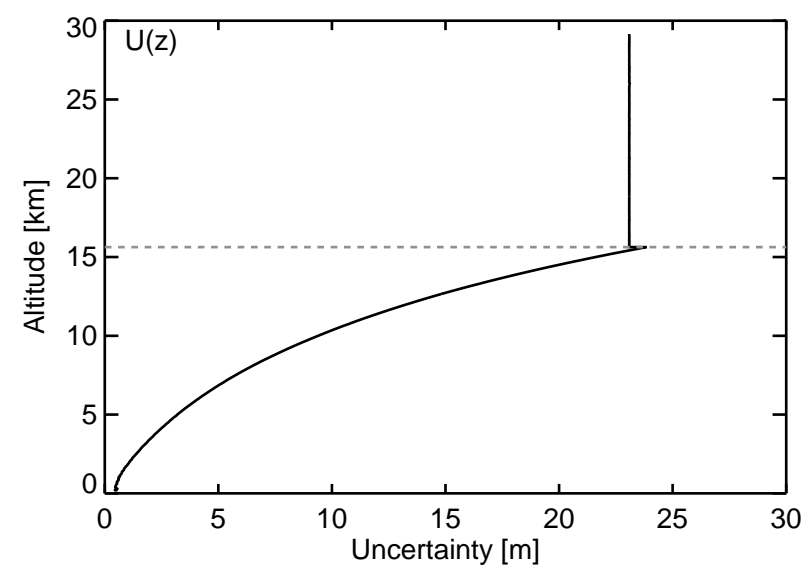

Figure 20. Uncertainty profile of the geometric altitude, $U(z)$. Between the surface and the switch altitude, indicated by the dashed grey line, $U(z)$ equals the uncertainty of the geometric pressure altitude; above that $U(z)$ equals the uncertainty of the GPS altitude. Same sounding as in Fig. 19.

\subsubsection{Calibration correction}

The correlated uncertainty associated with the temperaturedependent calibration correction $u_{\mathrm{c}}(\mathrm{cc})$ is given by

$u_{\mathrm{c}}(\mathrm{cc})=\frac{u\left(f_{\mathrm{cc}}\right)}{f_{\mathrm{cc}}} \mathrm{RH}^{*}$.

Here $f_{\mathrm{cc}}$ represents the calibration correction factor, $u\left(f_{\mathrm{cc}}\right)$ the uncertainty in $f_{\mathrm{cc}}$, and $\mathrm{RH}^{*}$ the calibrationcorrected relative humidity. Table 3 shows that the uncertainty associated with the calibration correction is approximately equal to the correction itself.

\subsubsection{Radiation dry bias correction}

The correlated uncertainty associated with the dry bias correction consists of two components, with the first component due to the uncertainty in the estimate of the radiation temperature error and the second due to the uncertainty in the radiation sensitivity factor $f$.

$u_{\mathrm{c}}\left(\mathrm{RC}_{T}\right)=\mathrm{RH}_{\mathrm{m}} \frac{p_{\mathrm{s}}(T+f(\Delta T+u(\Delta T)))-p_{\mathrm{s}}(T+f(\Delta T-u(\Delta T))}{2 \cdot p_{\mathrm{s}}(T)}$
$u_{\mathrm{c}}\left(\mathrm{RC}_{f}\right)=\mathrm{RH}_{\mathrm{m}} \frac{p_{\mathrm{s}}(T+(f+u(f)) \Delta T)-p_{\mathrm{s}}(T+(f-u(f)) \Delta T)}{2 \cdot p_{\mathrm{s}}(T)}$

Here $\mathrm{RH}_{\mathrm{m}}$ is the measured humidity, $T$ the ambient temperature, and $p_{\mathrm{s}}$ is the saturation vapour pressure over water according to Hyland and Wexler (1983). The uncertainty of the radiation temperature error $u(\Delta T)$ was discussed in Sect. 5.6 and equals the geometric sum of the uncertainty contributions listed in that section. The uncertainty in the radiation sensitivity factor $u(f)$ is given in Table 4 . The resulting total uncertainty of the dry bias correction is given by
Table 7. Approximate water vapour mixing ratios at the temperature level shown in Fig. 18.

\begin{tabular}{cc}
\hline Temperature $\left[{ }^{\circ} \mathrm{C}\right]$ & Water vapour mixing ratio $[\mathrm{ppmv}]$ \\
\hline-80 & $4-6$ \\
-60 & $1 \times 10^{1}-1 \times 10^{2}$ \\
-40 & $1 \times 10^{2}-5 \times 10^{2}$ \\
-20 & $1 \times 10^{3}-5 \times 10^{3}$ \\
0 & $3 \times 10^{3}-2 \times 10^{4}$ \\
\hline
\end{tabular}

Table 8. Summary of the uncertainty estimates for RS92 data for GRUAN processing (second column) and for Vaisala processing according to Vaisala (2007) (third column). The estimates for the vertically resolved GRUAN uncertainties on temperature and humidity are given for $25-30 \mathrm{~km}$ altitude. The GRUAN uncertainty on pressure is given for the switch altitude. The estimates for wind speed and direction are $1 \sigma$ statistical uncertainties. The right-most column lists the relevant sections/figures of this paper.

\begin{tabular}{llll}
\hline \multirow{2}{*}{ Parameter } & \multicolumn{2}{c}{ Uncertainty } & \multirow{2}{*}{ Reference } \\
& GRUAN & Vaisala & \\
\hline Temperature (night) & $0.15 \mathrm{~K}$ & $0.5 \mathrm{~K}$ & Sect. 5.6 \\
Temperature (day) & $0.6 \mathrm{~K}$ & $0.5 \mathrm{~K}$ & Fig. 9 \\
Relative humidity & $3-5 \% \mathrm{RH}$ & $5 \% \mathrm{RH}$ & Fig. 16 \\
Geopotential height & $10-50 \mathrm{~m}$ & - & Sect. 8.3 \\
Pressure & $0.6 \mathrm{hPa}$ & $0.6-1 \mathrm{hPa}$ & Sect. 8.3 \\
Wind speed & $0.4-1 \mathrm{~m} \mathrm{~s}^{-1}$ & $0.15 \mathrm{~m} \mathrm{~s}^{-1}$ & Sect. 9 \\
Wind direction & $1^{\circ}$ & $2^{\circ}$ & Sect. 9 \\
\hline * The GRUAN temperature uncertainty at night equals the calibration uncertainty.
\end{tabular}

the geometric sum of $u_{\mathrm{c}}\left(\mathrm{RH}_{T}\right)$ and $u_{\mathrm{c}}\left(\mathrm{RH}_{f}\right)$. The blue trace around $10-17 \mathrm{~km}$ in the middle and right panels of Fig. 16 shows that the absolute uncertainty due to the dry bias correction is largest near the tropopause.

\subsubsection{Time-lag correction}

The uncertainties associated with the time-lag correction function are the following:

- The correlated uncertainty due to the uncertainty in the time constant $u(\tau)$ is evaluated as the difference between time-lag correction profiles calculated with $\tau+u(\tau)$ and $\tau-u(\tau)$

$u_{\mathrm{c}, \mathrm{TL}}=0.5 \cdot|\mathrm{RH}(\tau+u(\tau))-\mathrm{RH}(\tau-u(\tau))|$,

with the uncertainty $u(\tau)$ given by Eq. (9).

- The uncorrelated uncertainty of the time-lag correction equals the statistical uncertainty (Eq. A5) that is calculated as part of the smoothing step in the time-lag correction.

The statistical uncertainty of the time-lag correction is approximately one to two times larger than the uncertainty due 
to $u(\tau)$, and it peaks at approximately $3 \% \mathrm{RH}$ in the coldest part of the profile.

The middle panel of Fig. 16 shows that for this sounding the time-lag correction is the dominant correction above approximately $10 \mathrm{~km}$, where it is approximately 2-3 times larger than the dry bias correction and up to 10 times larger than the calibration correction. Above the tropopause the time-lag correction and the dry bias correction work opposite, as the time-lag correction reduces the humidity at that altitude, whereas the dry bias correction increases the humidity.

The right panel of Fig. 16 shows that the correlated and uncorrelated uncertainties of the time-lag correction obviously peak where the time-lag correction itself is largest.

\subsection{Integrated precipitable water column}

The integrated precipitable water column (IPW) is retrieved from a radiosounding by summing the partial IPWs for each observation.

$\mathrm{IPW}=\frac{R_{\mathrm{d}}}{m_{\mathrm{H}_{2} \mathrm{O}}} \cdot \sum_{i=0}^{N} \frac{p_{\mathrm{s}}\left(T_{i}\right) \cdot \mathrm{RH}_{i}}{T_{i}}$,

with $R_{\mathrm{d}}$ being the gas constant for dry air, 287.04 $\mathrm{J} \mathrm{kg}^{-1} \mathrm{~K}^{-1}$; $m_{\mathrm{H}_{2} \mathrm{O}}$ the molecular mass of water, $18 \mathrm{~g} \mathrm{~mol}^{-1} ; p_{\mathrm{s}}$ the saturation vapour pressure in $\mathrm{hPa}$, calculated according to Hyland and Wexler (1983); and $T$ the ambient temperature in $\mathrm{K}$. The uncertainty of IPW is composed of the uncertainty in RH and the uncertainty in $p_{\mathrm{s}}$ due to the uncertainty in the ambient temperature. The major part of the IPW is contained in the lower part of the troposphere, say below $4 \mathrm{~km}$, where effects like time-lag and radiation dry bias are small, and the uncertainty in $\mathrm{RH}$ is dominated by the calibration uncertainty, which typically amounts to $3 \% \mathrm{RH}$. The uncertainty in the ambient temperature accounts for $1 \%$ uncertainty in IPW, and the total uncertainty in IPW amounts to 4-5\% RH.

\section{Comparisons}

\subsection{GRUAN-Vaisala}

In Fig. 17 the GRUAN data product is compared to the Vaisala product (FLEDT, DigiCora software version 3.64, however without the corrections for radiative heating that were introduced in 2011) for daytime and night-time soundings performed in Lindenberg in 2012. The GRUAN profiles used in this comparison have passed the GRUAN quality control (Sect. 4.1).

Figure 17 indicates good correspondence of the night-time temperature throughout the entire profile, which is expected because for night-time soundings the GRUAN radiation correction is identical to the Vaisala correction. During daytime the temperature difference between GRUAN and Vaisala is less than $0.05 \mathrm{~K}$ up to $25 \mathrm{~km}$ but increases above this altitude with the GRUAN temperature to more than $0.05 \mathrm{~K}$ colder than Vaisala at $30 \mathrm{~km}$ (see also Fig. 7).

The bottom panels of Fig. 17 shows that the average GRUAN humidity profile is moister than that of Vaisala. For night-time measurements the difference increases from $0 \%$ at the surface to approximately $7 \%$ near the tropopause at $10 \mathrm{~km}$. The sudden decrease of the GRUAN-Vaisala difference at the tropopause (around $12 \mathrm{~km}$ ) is due to the time-lag correction. In other parts of the troposphere the ambient temperatures either are too high for the time-lag effect to be relevant or the net effect of the time-lag correction averages out as a result of the random variation of the humidity gradients among the measurements.

The comparison of the daytime humidity profiles (lower right panel of Fig. 17) shows that the difference between GRUAN and Vaisala steadily increases between the surface and upper troposphere. In the troposphere, the daytime difference is approximately two times larger than at night (7\% vs. $15 \%$ at $10 \mathrm{~km}$ ), clearly a result of the daytime dry bias correction. The levelling-off at the tropopause is again the result of the time-lag correction, and after this the difference increases because of the dry bias correction. As noted in Sect. 6.7, RS92 measurements of stratospheric humidity are in principle meaningless because of the $100 \%$ uncertainty of the measured values.

\subsection{GRUAN RS92 - frost point hygrometers}

RS92 observations are compared to coincident reference measurements from two frost point hygrometers (FPs), the $\mathrm{CFH}$ and NOAA frost point hygrometer (FPH). FPs measures the dew/frost point of the ambient air with an accuracy of approximately $0.5 \mathrm{~K}$ and with a response time between $1 \mathrm{~s}$ in the troposphere and better than $20 \mathrm{~s}$ in the stratosphere (Vömel et al., 2007a). The locations of the sites at which coincident RS92-FP soundings were performed range from tropical to Arctic (Table 6). At Lindenberg, Sodankylä, and Boulder, dual soundings are performed on a regular basis. The RS92 profiles are processed by the GRUAN processing system, prior to comparison with the coincident $\mathrm{CFH}$ and FPH measurements. For the Alajuela soundings no .DC3DB data files are available. Instead edited Vaisala EDT product files are used that contain additional information on ground check corrections.

Figure 18 shows the comparison of GRUAN RS92 humidity profiles with coincident FP measurements. The comparison of the daytime data shows good agreement between GRUAN RS92 data and FP, with relative differences of less than $10 \%$ between the surface and the tropopause. However, the RS92 data at Boulder for temperatures below $-40{ }^{\circ} \mathrm{C}$ exhibit a systematic dry bias of 10-15\% with respect to the NOAA FPH data. The night-time comparison shows good agreement between GRUAN RS92 profiles and CFH data up to $-30{ }^{\circ} \mathrm{C}$, with a relative difference less than $10 \%$ for all 
sites (night-time soundings are not regularly performed in Boulder). For reference, the approximate water volume mixing ratios for the data presented in Fig. 18 are listed in Table 7 for various temperature levels.

Between -30 and $-50^{\circ} \mathrm{C}$ there is a systematic dry bias in the night-time RS92 data for all sites, which peaks at approximately $5 \%$ around $-40{ }^{\circ} \mathrm{C}$. A similar structure is observed between -30 and $-50{ }^{\circ} \mathrm{C}$ in the daytime Lindenberg data, but not for the other sites. This systematic bias resembles the empirical temperature-dependent calibration error reported by Vömel et al. (2007b), which is attributed to inaccuracies in the Vaisala calibration of the humidity sensor (Miloshevich et al., 2006). A correction for the temperature-dependent calibration error is already applied in the GRUAN processing, but its coefficients (Table 3 ) were derived from a data set that was considerably smaller than the one shown in Fig. 18.

The spread of the relative difference between GRUAN and FP humidity amounts to $20-25 \%$ in the upper troposphere (around $T=-60^{\circ} \mathrm{C}$ ), which is consistent with the uncertainty of the humidity above $10 \mathrm{~km}$ (Fig. 16).

\section{Geopotential height}

The RS92 is equipped with both a pressure sensor and a GPS receiver, which provide two independent methods to retrieve the vertical coordinate. The GPS receiver provides geometric altitude above the WGS-84 reference ellipsoid at an accuracy of roughly $10-20 \mathrm{~m}$. The accuracy of the pressure sensor is $1 \mathrm{hPa}$ for $p>100 \mathrm{hPa}$ and $0.6 \mathrm{hPa}$ for $p<100 \mathrm{hPa}$ (Vaisala, 2007). For radiosoundings, the vertical coordinate usually is expressed as geopotential height, due to its suitability for meteorological models. The geopotential height can be calculated either from the pressure or from the geometric altitude. Using these relationships in reverse, the pressure can be also inferred from the geometric altitude. In accordance with the GRUAN philosophy, this measurement redundancy is used to determine the vertical coordinate.

The calculation of the geopotential height from pressure measurements is given in Appendix B4.

\subsection{GPS-based altitude}

For radiosondes equipped with a GPS receiver, such as the RS92, it is possible to determine the geopotential height from the GPS readings using Eq. (B7). However, we have discovered that the GPS receiver of the RS92 has accuracy problems (jumps of several decametres) in the first few kilometres above ground level, presumably due to interference by GPS signals that are reflected by the surface. Therefore, the GRUAN processing uses both the pressure and the GPS receiver to construct the altitude scale, using the highestquality data available in two altitude ranges. Pressure readings are used at lower altitudes due to their better signal-tonoise ratios at high pressures, and at higher altitudes the GPS readings are used. The GRUAN processing uses the GPSbased WGS- 84 altitudes, $z_{\text {GPS }}$, that are calculated from the $x y z$ data in the GPSDCC_RESULT table. The WGS-84 altitude data are converted to geometric altitude by correcting these using the geometric altitude derived from the pressure measurements, instead of correcting using the station's GPS receiver, as is done in the Vaisala processing. This means that the accuracy of the altitude scale is directly connected to the accuracy of the pressure measurements, and therefore it is essential that reliable metadata are available concerning the altitude and accuracy of the station barometer and the altitude of the GC25 unit.

\subsection{GRUAN processing}

The GRUAN processing uses the following steps to construct the geopotential height from the pressure and the GPS data, which will be further explained below.

1. Calculate the geometric altitude $z_{p}$ from the pressure data.

2. Estimate the noise in $z_{p}$ and $z_{\mathrm{GPS}}$.

3. Determine the altitude where the noise in $z_{p}$ exceeds the noise in $z_{\text {GPS }}$ ("switch altitude").

4. Determine the offset between $z_{p}$ and $z_{\mathrm{GPS}}$ at the switch altitude.

5. Join $z_{p}$ and $z_{\mathrm{GPS}}$ at the switch altitude: $z=$ $\left[z_{p}, z_{\mathrm{GPS}}+\right.$ offset $]$.

6. Convert geometric altitude $z$ into a smoothed pressure profile using Eq. (B6).

7. Calculate the geopotential height from the smoothed pressure profile using Eq. (B3).

This scheme uses the redundant altitude measurements by the pressure and GPS receiver, and improves the limited accuracy of the RS92 GPS data in the first few kilometres, as well as the limited accuracy of the pressure sensor near the ceiling altitude. As a result the geopotential height, the geometric altitude and the pressure scale are all consistent.

The noise in $z_{p}$ and $z_{\text {GPS }}$ is the statistical noise calculated for a 100-point-wide window, using Eq. (A5). This noise represents the random uncertainty in the geometric altitudes. Figure 19 shows the noise profiles of $z_{p}$ and $z_{\mathrm{GPS}}$; this illustrates the better signal-to-noise performance of the pressure sensor in the lower half of the sounding. The switch between pressure sensor and GPS data (switch altitude) occurs at the first level above $3 \mathrm{~km}$ where the statistical noise of $z_{\mathrm{GPS}}, u_{\mathrm{r}}\left(z_{\mathrm{GPS}}\right)$, exceeds the statistical noise of $z_{p}, u_{\mathrm{r}}\left(z_{p}\right)$, by less than $20 \%$. The switch altitude lies mainly between 9 and $17 \mathrm{~km}$. In the profile shown in Fig. 19 the switch altitude is at $15.1 \mathrm{~km}$. The offset has a typical value of approximately $50 \mathrm{~m}$. 


\subsection{Corrections and uncertainties}

Inaccuracies and uncertainties of the pressure measurements directly affect the accuracy and uncertainty of the geopotential height. The calibration uncertainty of the pressure sensor is composed of the uncertainty given by Vaisala and the uncertainty of the station barometer which is used to recalibrate the pressure sensor during the ground check. A possible bias of the pressure sensor is determined from the comparison with the GPS data, as will be discussed below.

During ground check the pressure sensor is recalibrated against the station barometer. The ratio of the readings of the station barometer and the RS92 pressure sensor during ground check yields a correction factor $c=p_{\text {station }} / p_{\text {RS92,GC25 }}$, which the DigiCora software applies to the entire pressure profile during the data recording. These recalibrated pressure data are used in the GRUAN processing.

\subsubsection{Uncertainty in launch altitude}

The station barometer and launch site may be at different elevations; e.g. at Lindenberg observatory this altitude difference is approximately $10 \mathrm{~m}$. Therefore the altitude of the launch site $h_{0}$ is calculated from the pressure difference between the sonde's first pressure reading after launch and the simultaneous reading of the station barometer, using the hydrostatic equation

$h_{0}=h_{\text {station }}+100 \cdot \frac{p_{\text {station }}-p_{\text {launch }}}{\rho_{0} \gamma\left(h_{\text {station }}, \phi_{\text {station }}\right)}$.

Here, $\gamma\left(h_{\text {station }}, \phi_{\text {station }}\right)$ is the local gravity, and $\rho_{0}$ is the air density at the launch site, which is derived from the sonde's pressure and temperature reading at launch. The uncorrelated uncertainty $U_{\mathrm{u}}\left(h_{0}\right)$ of $h_{0}$ is the geometric sum of the uncertainty of the station barometer and the random noise of the pressure sensor at launch $u_{\mathrm{r}}\left(p_{1}\right)$.

$u_{\mathrm{u}}\left(h_{0}\right)=\sqrt{u_{\mathrm{u}, \text { launch }}^{2}\left(z_{p}\right)+\left(100 \cdot u_{\mathrm{r}}\left(p_{1}\right) /\left(\rho_{0} \gamma\left(h_{\text {station }}, \phi_{\text {station }}\right)\right)\right)^{2}}$

$u_{\mathrm{r}}\left(p_{1}\right)$ is determined statistically from 100 pressure readings prior to launch and from the noise in the lowest part of the pressure-altitude profile, under the implicit assumption that the ambient pressure is stable during the final $2 \mathrm{~min}$ before launch. The uncertainty of the station barometer includes the uncertainty at which its altitude is known.

\subsubsection{Uncertainty of the pressure sensor}

The correlated uncertainty of the pressure sensor after the ground check recalibration is the geometric sum of the absolute calibration uncertainty of the pressure sensor, $u_{\mathrm{cal}}=0.4 \mathrm{hPa}(k=2)$ (Vaisala, 2007), and the difference between station barometer and the RS92 pressure sensor during ground check:

$u_{\mathrm{c}, \mathrm{GC} 25}(p)=\sqrt{u_{\mathrm{cal}}^{2}+\left(\Delta p_{\mathrm{GC} 25} / 3\right)^{2}}$.
The factor of 3 in the denominator of $\Delta p_{\mathrm{GC} 25}$ is in accordance with Sect. 4.4.5 of JCGM/WG 1 (2008).

The altitude-dependent bias of the pressure sensor is determined by comparing the geometric pressure altitude $z_{p}$ and the recalibrated GPS altitude $z_{\text {GPS }}$ along the entire profile, using the barometric equation

$\Delta p=p\left[\exp \left(\frac{\gamma \Delta z}{R_{\mathrm{d}} T}\right)-1\right] \quad$ with $\Delta z=z_{p}-z_{\mathrm{GPS}}$.

The bias $\Delta p$ adds to the correlated uncertainty of the pressure $U_{\mathrm{c}}(p)$. Below the switch altitude $\Delta p$ is linearly interpolated to the calibration uncertainty $U_{\mathrm{c}, \mathrm{GC} 25}(p)$ at the surface.

\subsubsection{Uncertainty of the geometric pressure altitude}

The uncertainty of the geometric pressure altitude consists of a random and a correlated component, with the random component the statistical noise of $z_{p}$. The correlated component follows from evaluating the effect of the bias of the pressure sensor $\Delta p$ :

$u_{\mathrm{c}}\left(z_{p}\right)=0.5 \times(z(p+\Delta p)-z(p-\Delta p))$,

where Eq. (B3) with $\gamma(z, \phi)$ given by Eq. (B5) is used to calculate the geometric pressure altitude.

The cumulative uncertainty in the geometric pressure altitude follows from the geometric sum of all components:

$u\left(z_{p}\right)=\sqrt{u_{\mathrm{u}}\left(h_{0}\right)^{2}+u_{\mathrm{r}}\left(z_{p}\right)^{2}+u_{\mathrm{c}}\left(z_{p}\right)^{2}}$,

where $u_{\mathrm{u}}\left(h_{0}\right)$ is given by Eq. (20). The uncertainty in the launch altitude and the random uncertainty in the geometric pressure altitude are small $(<2 \mathrm{~m})$ compared to the correlated uncertainty $u_{\mathrm{c}}\left(z_{p}\right)$, meaning that the uncertainty of the geometric pressure altitude $u\left(z_{p}\right)$ basically is determined by the bias of the pressure sensor $\Delta p$.

\subsubsection{Uncertainty of the GPS altitude}

The random uncertainty of the GPS altitude is the statistical noise of $z_{\text {GPS }}$. The correlated uncertainty of $z_{\text {GPS }}$ is the uncertainty of the recalibration (offset) at the switch altitude, which is applied to the entire GPS altitude profile. The uncertainty of this offset is composed of the statistical uncertainty of $z_{p}-z_{\mathrm{GPS}}$ at the switch altitude, $u_{\mathrm{c}}$ (offset), and the correlated uncertainty of the geometric pressure altitude at the switch altitude $u_{\mathrm{c}, \text { switch }}\left(z_{p}\right)$. The cumulative uncertainty of the GPS altitude is given by

$u\left(z_{\mathrm{GPS}}\right)=\sqrt{u_{\mathrm{r}}\left(z_{\mathrm{GPS}}\right)^{2}+u_{\mathrm{c}}(\mathrm{offset})^{2}+u_{\mathrm{c}, \text { switch }}\left(z_{p}\right)^{2}}$.

The random uncertainty of the GPS altitude is small compared to the correlated uncertainties. This means that $u\left(z_{\mathrm{GPS}}\right)$ is nearly constant along the profile, with its value determined by the uncertainties $u_{\mathrm{c}}$ (offset) and $u_{\mathrm{c} \text {, switch }}\left(z_{p}\right)$ at the switch altitude. 


\subsubsection{Cumulative uncertainties}

The resulting uncertainty profile of the geometric altitude, $u(z)$, is constructed from $u\left(z_{p}\right)$ below the switch altitude and $u\left(z_{\mathrm{GPS}}\right)$ above. From this the uncertainty of the pressure is calculated, using the barometric equation

$u(p)=-\frac{\gamma_{45} \cdot p}{R_{\mathrm{d}} \cdot T} \cdot \exp \left(-\frac{\gamma_{45} \cdot \mathrm{d} z}{R_{\mathrm{d}} \cdot T}\right) \cdot u(z)$.

This is added to the uncertainty of the pressure sensor $u_{\mathrm{c}, \mathrm{GC} 25}(p)$ to yield the total altitude-dependent uncertainty of the pressure. The uncertainty of the geopotential height is identical to the uncertainty in the geometric altitude.

Figure 20 shows that the uncertainty $u(z)$ increases with altitude below the switch altitude, which reflects the increasing importance of the pressure sensor's inaccuracy with decreasing pressure. The uncertainty $u(z)$ at the switch altitude is determined by the bias of the pressure sensor (Sect. 8.3.3). Above the switch altitude, the uncertainty is constant and determined by the uncertainty of the offset between the geometric pressure altitude and the GPS altitude at the switch altitude (Sect. 8.3.4). The uncertainty $u(z)$ at the switch altitude is different for each sounding, and its value typically ranges from 10 to $50 \mathrm{~m}$. The uncertainty $u(p)$ at this altitude typically is around $0.6 \mathrm{hPa}$.

\section{Wind}

The DigiCora system retrieves the magnitudes of the zonal and meridional wind vectors, $u$ and $v$ respectively, from the Doppler shift in the GPS carrier signal. In the GRUAN processing, these vectors are smoothed and converted into wind speed and direction.

The raw data of the vector components $u$ and $v$ are noisy due to the radiosonde's pendulum motion and the noise of the GPS data. The noise in $u$ and $v$ is reduced by a lowpass digital filter, similar to the one employed in the time-lag correction (Sect. 6.6). This smoothing reduces the temporal resolution of the wind data to $40 \mathrm{~s}$ and provides the statistical uncertainties $\delta_{u}$ and $\delta_{v}$ (see Eq. A5), which are $0.4-1 \mathrm{~m} \mathrm{~s}^{-1}$. This labelling of the uncertainty is used to distinguish it from the wind vector components $u$ and $v$.

Using these statistical uncertainties, the uncertainty of the wind direction $u(\phi)$ is given by

$u(\phi)=\frac{180}{\pi} \frac{\sqrt{\delta_{u}^{2}+\delta_{v}^{2}}}{\left(1+(u / v)^{2}\right)|v|}$

and the uncertainty of the wind speed $u(s)$ by

$u(s)=\sqrt{\frac{\left(u \delta_{u}\right)^{2}+\left(v \delta_{v}\right)^{2}}{u^{2}+v^{2}}}$.

Typical values of these uncertainties are $0.4-1 \mathrm{~m} \mathrm{~s}^{-1}$ for $u(s)$ and $1^{\circ}$ for $u(\phi)$.
In the case of negligible wind, when $u$ and $v$ approach 0 , the value of Eq. (27) becomes very large because of the factor $v$ in the denominator. For such cases, the absolute value of $u(\phi)$ is limited to $180^{\circ}$.

\section{Summary and outlook}

Currently, 13 out of 15 GRUAN sites launch the RS92 on a regular basis. Other radiosondes that are employed include Meteolabor SRS34, Modem M10, and Meisei RS-11G. The GRUAN data product for the Vaisala RS92 radiosonde was developed to meet the criteria for reference measurements: traceability, the availability of metadata, and best estimates of the measurement uncertainty. Traceability in this respect means the use of well-documented correction algorithms and that the measurements are traceable to SI standards. In this paper the algorithms that are used in version 2 of the GRUAN processing were described, together with a discussion of the estimated measurement uncertainties. Earlier studies have shown that the dominant error sources for the RS92 temperature and humidity measurements are solar radiation, causing a temperature error and a dry bias, and time-lag of the humidity sensor. A novel aspect of the GRUAN data product is the availability of vertically resolved uncertainty estimates.

Laboratory experiments were performed in Lindenberg to measure the response of the RS92 sensors to solar irradiance at various ambient pressures. These resulted in a radiation correction model that depends on pressure, ascent speed, and simulated actinic flux. The GRUAN correction for the radiation temperature error is consistent with the Vaisala correction, meaning that the Vaisala correction is within the GRUAN uncertainty range.

The differences between daytime temperature profiles processed by GRUAN and Vaisala are consistent with the difference between the respective radiation correction models, and they are within the estimated uncertainty of $0.3 \mathrm{~K}$ at $30 \mathrm{~km}$.

The Vaisala GC25 recalibration of the humidity sensors is not applied in the GRUAN processing because the recalibration introduces a systematic bias in the entire humidity profile.

The correction for the radiation dry bias uses the same method as the radiation temperature correction to estimate the heating of the sensor, with an additional factor to account for the larger sensitivity of the humidity sensor to irradiance. Near the tropopause, the time-lag correction is the dominant correction to the humidity, being up to three times larger than the dry bias correction. However, the uncertainty associated with the time-lag correction is smaller than the uncertainty of the dry bias and temperature-dependent calibration corrections. In the lower part of the sounding the calibration uncertainty of the humidity sensor dominates. Comparison of GRUAN- and Vaisala-processed data shows that night-time GRUAN profiles are up to $5 \%$ moister than Vaisala in the upper troposphere, which is due to the temperature-dependent 
calibration correction. For daytime data the GRUAN profiles are up to $15 \%$ moister due to the additional dry bias correction.

The calibration uncertainty of the humidity sensors is the dominant uncertainty for the retrieval of the integrated precipitable water column from radiosoundings, which is $4-5 \%$. The uncertainties and corrections to the humidity profile limit the accuracy of the measurement of water vapour in the upper troposphere, thereby directly affecting the estimate of the radiation balance.

Redundant measurements with different instrument types are needed to detect systematic biases. Comparison of GRUAN humidity profiles with frost point hygrometer $(\mathrm{CFH}$ and NOAA FPH) data shows agreement within $15 \%$ up to the tropopause. No systematic biases occur, apart from a $5 \%$ dry bias for GRUAN data around $-40{ }^{\circ} \mathrm{C}$ at night.

The geopotential height is determined from both the pressure sensor and the GPS data. In the lower half of the sounding the pressure sensor is used because of its better signalto-noise performance. The uncertainty of the geopotential height is approximately $1 \mathrm{~m}$ near the surface, and it increases to approximately $30 \mathrm{~m}$ in the stratosphere. The calibration of the altitude scale is tied to the station barometer, which necessitates reliable metadata regarding its altitude and accuracy.

Table 8 summarizes the uncertainty estimates of the PTU, geopotential height, and wind parameters that were presented in this paper and lists these together with the numbers given in Vaisala (2007). The GRUAN and Vaisala uncertainty estimates for temperature, humidity, pressure, and wind direction are consistent. The GRUAN temperature uncertainty at night equals the calibration uncertainty, due to the absence of the radiation correction. The GRUAN uncertainty estimate for the wind speed (up to $1 \mathrm{~m} \mathrm{~s}^{-1}$ ) is considerably larger than the Vaisala uncertainty $\left(0.15 \mathrm{~m} \mathrm{~s}^{-1}\right)$.

\subsection{Consequences for sounding operations}

Based on the topics discussed in this paper, we define the following recommendations for performing reference radiosoundings:

- We strongly recommend an additional ground check for radiosondes in the standard humidity chamber, as this helps to track changes in the RS92 humidity sensors. Analysis of the SHC checks performed at Lindenberg shows that the bias of the RS92 humidity sensor at $100 \%$ RH has drifted by $4 \%$ over 8 years. Such systematic effects of instrumental origin are important for observing climate trends.

- The proper operational procedure for preparing the radiosonde as prescribed by the manufacturer should be followed. The additional ground check in the SHC revealed that at one GRUAN station the reconditioning of the sensors was skipped, leading to a dry bias of several percent $\mathrm{RH}$.

- The recalibration of the humidity sensors in the GC25 calibration unit should be reversed before processing the raw data because the recalibration introduces a systematic bias in the humidity profile. The Vaisala processing software applies the GC25 recalibration to the raw data before it is stored. It is not possible to read raw data from the sensor without the application of the recalibration. To get true raw measurements, the recalibration must be unapplied, which is possible because the recalibration corrections are stored as metadata in the Vaisala .DC3DB data file.

- Balloons should be filled with enough lifting gas to ensure an ascent speed between 5 and $7 \mathrm{~ms}^{-1}-$ in accordance with the WMO recommendation - as too-low ascent speeds lead to larger temperature errors due to radiation.

- Rigs with multiple instruments should be configured so as to minimize additional radiation on the RS92 sensors by reflection from the styrofoam housing, as this leads to biases in the temperature and humidity profiles.

- In order to minimize temperature spikes, an unwinder of sufficient length $(>30 \mathrm{~m}$ ) should be used.

For comparisons with Vaisala-processed data one should use data from the FLEDT table, where the relative humidity data are stored as floating point numbers, instead of the EDT table, where the RH data are stored as integers.

\subsection{Future improvements to data processing}

For the next version of the GRUAN data processing for the RS92 the following improvements are foreseen:

- use of the measurement data from the additional ground check in the SHC to correct (scale) the humidity profile;

- an update of the radiation temperature error correction, based on additional experiments and analyses of the radiation temperature error;

- an update of the coefficients of the temperaturedependent calibration correction based on the currently available intercomparisons between RS92 and frost point hygrometer data.

After the implementation of these improvements in the processing, the GRUAN sounding archive will be reprocessed, resulting in an updated, homogeneous data set, which is a consequence of the GRUAN philosophy to store raw measurement data and the associated metadata. The GRUAN approach also provides guidelines for dealing with the limitations of in situ measurements - namely by characterizing, 
and correcting for, error sources and by providing best possible estimates of vertically resolved measurement uncertainties. Furthermore, GRUAN-stipulated measurement redundancy is essential for validating data and characterization of error sources. It is our aim that the GRUAN data processing described in this paper sets an example for other observational meteorological data products. GRUAN data are available at www.gruan.org/data. 


\section{Appendix A: Uncertainty formulas}

For a set of measurements $S$ with zero expectation value the bias $b$ is given by

$b=\frac{1}{N} \sum_{i}^{N} s_{i}$

and the uncertainty $u(b)$ of the bias is estimated by calculating the statistical uncertainty of the average (Sect. 4.2.3 of JCGM/WG 1, 2008):

$u(b)=\sqrt{\frac{1}{N(N-1)} \sum_{i}^{N}\left(s_{i}-b\right)^{2}}=\frac{\sigma_{b}}{\sqrt{N}}$,

with $\sigma_{b}$ being the standard deviation of the ensemble.

Smoothing, or low-pass filtering, involves convolving the data points of the profile with a Gaussian-shaped averaging kernel $c$ of $2 M+1$ elements.

$s_{i}=\sum_{j=-M}^{M} c_{j} s_{i+j}$

The kernel is normalized $\left(\sum c_{j}=1\right)$ and symmetric $\left(c_{-j}=c_{j}\right)$, and the kernel width is related to the smoothing power of the filter; i.e. the wider the kernel, the smoother the filtered signal. In order to calculate the standard deviation when filters with non-identical kernel elements are employed, the effective sample size $N^{\prime}$ is introduced:

$N^{\prime}=\left(\sum_{j=-M}^{M} c_{j}^{2}\right)^{-1}$.

For a low-pass filter, $N^{\prime}$ corresponds to the width $\sigma$ of the Gaussian-shaped kernel function. The estimated statistical uncertainty of the smoothed data point $\bar{s}_{i}$ is then given by

$u\left(\bar{s}_{i}\right)=\sqrt{\frac{N^{\prime}}{N^{\prime}-1} \sum_{j=-M}^{M} c_{j}^{2}\left(s_{i+j}-\bar{s}_{i}\right)^{2}}$.

Uncertainties from independent sources that all pertain to the same measurement parameter can be added geometrically to yield the total uncertainty of that parameter:

$u(x)=\sqrt{\sum_{f} u\left(x_{f}\right)^{2}}$,

where $f$ denotes a source of uncertainty.

\section{Appendix B: Geopotential height}

\section{B1 Geopotential height from pressure}

The geopotential height $H$ is calculated by integrating the local gravity normal to the geoid $\gamma(z, \phi)$ between mean sea level $(z=0)$ and the geometric altitude $(z=Z)$ :

$H(Z, \phi)=\frac{1}{\gamma_{45}} \int_{0}^{Z} \gamma(z, \phi) \mathrm{d} z$,

with $\phi$ being the geographic latitude, and $\gamma_{45}=$ $9.80665 \mathrm{~m} \mathrm{~s}^{-2}$ the normal gravity at $45.542^{\circ}$ latitude.

Rewriting the hydrostatic equation using the ideal gas law to eliminate the density gives the geopotential in differential form:

$\gamma(z, \phi) \mathrm{d} z=-R_{\mathrm{d}} T_{\mathrm{v}} \frac{\mathrm{d} p}{p}$,

with $p$ being pressure; $R_{\mathrm{d}}$ the gas constant for dry air $287.04 \mathrm{~J} \mathrm{~kg}^{-1} \mathrm{~K}^{-1}$; and $T_{\mathrm{v}}$ the virtual temperature. Integration and division by $\gamma_{45}$ yields the hypsometric equation, with which the geopotential height difference between two radiosonde measurements can be calculated using the observed pressure, temperature, and RH only (HofmannWellenhof and Moritz, 2006).

$\Delta H_{1,2}=\frac{R_{\mathrm{d}}}{\gamma_{45}} \bar{T}_{\mathrm{v}} \log _{10}\left(\frac{p_{1}}{p_{2}}\right)$

Here $\bar{T}_{\mathrm{v}}$ denotes the average virtual temperature between pressure levels $p_{1}$ and $p_{2}$. The virtual temperature accounts for water vapour and as such amends the gas constant for dry air. It is given by

$\bar{T}_{\mathrm{v}}=\frac{\bar{T}}{1-0.01 \cdot \operatorname{RH}(1-0.622) p_{\mathrm{s}} / \bar{p}}$,

with $p_{\mathrm{s}}$ being the saturation pressure for water vapour at temperature $\bar{T}$, and 0.622 the ratio of the molar masses of water vapour and dry air. The average temperature of the layer is $\bar{T}=\left(T_{1}+T_{2}\right) / 2$, and the average pressure is $\bar{p}=\sqrt{p_{1} p_{2}}$. Subsequently, the geopotential height at a certain radiosonde level is obtained by summing Eq. (B3) for all measurements between the surface and the desired level and adding the geopotential height of the launch site. In case of prolonged data gaps, the $T$ and $\mathrm{RH}$ profiles need to be interpolated between the available measurements, and failure to detect the real structure of the profiles within the gaps will introduce an error in the retrieved geopotential height above these gaps.

\section{B2 Geometric altitude from pressure}

The geometric altitude derived from the pressure measurements $z_{p}$ is calculated using Eq. (B3), where $\gamma_{45}$ is replaced by $\gamma\left(z_{j}, \phi\right) \cdot \gamma\left(z_{j}, \phi\right)$ is given by the Western European Legal Metrology Cooperation (WELMEC) formula (Thulin, 1992):

$$
\begin{aligned}
\gamma\left(z_{j}, \phi\right) & =9.780318 \cdot\left(1+5.3024 \cdot 10^{-3} \sin ^{2}(\phi)\right. \\
& \left.-5.8 \cdot 10^{-6} \sin ^{2}(2 \phi)\right)-3.085 \cdot 10^{-6} z_{j} .
\end{aligned}
$$

In order to prevent recursive calculation, $z_{j}$ is taken from the GPS-based geometric altitude $z_{\mathrm{GPS}}$. 


\section{B3 Pressure from geometric altitude}

The pressure difference between two altitude levels is calculated by inverting Eq. (B3), yielding the barometric equation, and using $\gamma(z, \phi)$ (Eq. B5) instead of $\gamma_{45}$ :

$\Delta p_{j}=p_{j}\left[\exp \left(\frac{\gamma\left(z_{j}, \phi\right) \cdot \Delta z_{j}}{R_{\mathrm{d}} \cdot \bar{T}_{v, j}}\right)-1\right]$.

\section{B4 Geopotential height from geometric altitude}

For the calculation of the geopotential height from the geometric height, the altitude dependence of the gravity $\gamma(z, \phi)$ and the latitude dependence of the Earth's radius $R(\phi)$ should be taken into account (Hofmann-Wellenhof and Moritz, 2006).

$H(Z, \phi)=\frac{\gamma_{\mathrm{s}}(\phi)}{\gamma_{45}} \cdot \frac{R(\phi) \cdot Z}{R(\phi)+Z}$
Here $\gamma_{\mathrm{s}}(\phi)$ is Somigliana's equation for normal gravity of the surface of an ellipsoid:

$\gamma_{\mathrm{s}}(\phi)=\gamma_{\mathrm{e}}\left(\frac{1+k_{\mathrm{s}} \cdot \sin ^{2}(\phi)}{\sqrt{1-e^{2} \cdot \sin ^{2}(\phi)}}\right)$,

with $k_{\mathrm{s}}=1.9318 \times 10^{-3}$ being Somigliana's constant, $e=$ 0.081819 the eccentricity of the WGS-84 ellipsoid, and $\gamma_{\mathrm{e}}=$ $9.780325 \mathrm{~m} \mathrm{~s}^{-2}$ the equatorial gravity. The Earth's radius $R(\phi)$ is approximated by

$R(\phi)=\frac{6378.137}{1.006803-0.006706 \cdot \sin ^{2}(\phi)} \mathrm{km}$. 
Acknowledgements. The authors wish to thank the operators at the Lindenberg observatory for dutifully performing reference radiosoundings according to the GRUAN standards.

Edited by: R. Sica

\section{References}

Bock, O., Bosser, P., Bourcy, T., David, L., Goutail, F., Hoareau, C., Keckhut, P., Legain, D., Pazmino, A., Pelon, J., Pipis, K., Poujol, G., Sarkissian, A., Thom, C., Tournois, G., and Tzanos, D.: Accuracy assessment of water vapour measurements from in situ and remote sensing techniques during the DEMEVAP 2011 campaign at OHP, Atmos. Meas. Tech., 6, 2777-2802, doi:10.5194/amt-6-2777-2013, 2013.

Bojinski, S., Verstraete, M., Peterson, T. C., Richter, C., Simmons, A., and Zemp, M.: The concept of Essential Climate Variables in support of climate research, applications, and policy, B. Am. Meteorol. Soc., 95, 1431-1443, doi:10.1175/bams-d-13-00047.1, 2014.

Calbet, X., Kivi, R., Tjemkes, S., Montagner, F., and Stuhlmann, R.: Matching radiative transfer models and radiosonde data from the EPS/Metop Sodankylä campaign to IASI measurements, Atmos. Meas. Tech., 4, 1177-1189, doi:10.5194/amt-4-1177-2011, 2011.

Dai, A., Wang, J., Thorne, P. W., Parker, D. E., Haimberger, L., and Wang, X. L.: A New Approach to Homogenize Daily Radiosonde Humidity Data, J. Climate, 24, 965-991, 2010.

Durre, I., Williams, C. N., Yin, X. G., and Vose, R. S.: Radiosonde-based trends in precipitable water over the Northern Hemisphere: An update, J. Geophys. Res.-Atmos., 114, doi:10.1029/2008JD010989, 2009.

Elliott, W. P. and Gaffen, D. J.: On the utility of radiosonde humidity archives for climate studies, B. Am. Meteorol. Soc., 72, 15071520, 1991.

Free, M., Seidel, D. J., Angell, J. K., Lanzante, J., Durre, I., and Peterson, T. C.: Radiosonde Atmospheric Temperature Products for Assessing Climate (RATPAC): A new data set of large-area anomaly time series, J. Geophys. Res.-Atmos., 110, doi:10.1029/2005JD006169, 2005.

Gallice, A., Wienhold, F. G., Hoyle, C. R., Immler, F., and Peter, T.: Modeling the ascent of sounding balloons: derivation of the vertical air motion, Atmos. Meas. Tech., 4, 2235-2253, doi:10.5194/amt-4-2235-2011, 2011.

GCOS-112: GCOS Reference Upper-Air Network (GRUAN): Justification, requirements, siting and instrumentation options, Technical Document 112, WMO TD No.1379, http://www.wmo.int/ pages/prog/gcos/Publications/gcos-112.pdf (last access: December 2014), 2007.

Haimberger, L., Tavolato, C., and Sperka, S.: Homogenization of the Global Radiosonde Temperature Dataset through Combined Comparison with Reanalysis Background Series and Neighboring Stations, J. Climate, 25, 8108-8131, 2012.

Hajj, G. A., Ao, C. O., Iijima, B. A., Kuang, D., Kursinski, E. R., Mannucci, A. J., Meehan, T. K., Romans, L. J., de la Torre Juarez, M., and Yunck, T. P.: CHAMP and SAC-C atmospheric occultation results and intercomparisons, J. Geophys. Res.-Atmos., 109, doi:10.1029/2003JD003909, 2004.
Hodge, M. W.: Superadiabatic lapse rates of temperature in radiosonde observations, Mon. Weather Rev., 84, 103-106, 1956.

Hofmann-Wellenhof, B. and Moritz, H.: Physical Geodesy, Springer Verlag, Berlin, Germany, 2nd Edn., 2006.

Hyland, R. and Wexler, A.: Formulations for the thermodynamic properties of the saturated phases of $\mathrm{H}_{2} \mathrm{O}$ from $173.15 \mathrm{~K}$ to 473.15 K, ASHRAE Tran., 89, 500-519, 1983.

Immler, F. and Sommer, M.: GRUAN Technical document 4 - Brief description of the RS92 GRUAN Data Product (RS92-GDP), Technical report, GRUAN Lead Centre, Lindenberg, Germany, 2014, version 2.0, 2014.

Immler, F. J., Dykema, J., Gardiner, T., Whiteman, D. N., Thorne, P. W., and Vömel, H.: Reference Quality Upper-Air Measurements: guidance for developing GRUAN data products, Atmos. Meas. Tech., 3, 1217-1231, doi:10.5194/amt-3-1217-2010, 2010.

JCGM/WG 1: Evaluation of measurement data - Guide to the expression of uncertainty in measurement, International Bureau of Weights and Measures / Bureau International des Poids et Mesures, http://www.bipm.org/utils/common/documents/jcgm/ JCGM_100_2008_E.pdf (last access: December 2014), 2008.

Key, J. R. and Schweiger, A. J.: Tools for atmospheric radiative transfer: Streamer and FluxNet, Computer and Geoscience, 24, 443-451, 1998.

Kursinski, E. R., Hajj, G. A., Schofield, J. T., Linfield, R. P., and Hardy, K. R.: Observing Earth's atmosphere with radio occultation measurements using the Global Positioning System, J. Geophys. Res.-Atmos., 102, 23429-23465, 1997.

Leblanc, T., Walsh, T. D., McDermid, I. S., Toon, G. C., Blavier, J.-F., Haines, B., Read, W. G., Herman, B., Fetzer, E., Sander, S., Pongetti, T., Whiteman, D. N., McGee, T. G., Twigg, L., Sumnicht, G., Venable, D., Calhoun, M., Dirisu, A., Hurst, D., Jordan, A., Hall, E., Miloshevich, L., Vömel, H., Straub, C., Kampfer, N., Nedoluha, G. E., Gomez, R. M., Holub, K., Gutman, S., Braun, J., Vanhove, T., Stiller, G., and Hauchecorne, A.: Measurements of Humidity in the Atmosphere and Validation Experiments (MOHAVE)-2009: overview of campaign operations and results, Atmos. Meas. Tech., 4, 2579-2605, doi:10.5194/amt-42579-2011, 2011.

Luers, J. K.: Estimating the temperature error of the radiosonde rod thermistor under different environments, J. Atmos. Ocean. Tech., 7, 882-895, 1990.

Luers, J. K.: Temperature Error of the Vaisala RS90 Radiosonde, J. Atmos. Ocean. Tech., 14, 1520-1532, 1997.

McCarthy, M. P., Thorne, P. W., and Titchner, H. A.: An analysis of tropospheric humidity trends from radiosondes, J. Climate, 22, 5820-5838, 2009.

Miloshevich, L. M., Paukkunen, A., Vömel, H., and Oltmans, S. J.: Development and Validation of a Time-Lag Correction for Vaisala Radiosonde Humidity Measurements, J. Atmos. Ocean. Tech., 21, 1305-1327, 2004.

Miloshevich, L. M., Vömel, H., Whiteman, D. N., Lesht, B. M., Schmidlin, F. J., and Russo, F.: Absolute accuracy of water vapor measurements from six operational radiosonde types launched during AWEX-G and implications for AIRS validation, J. Geophys. Res.-Atmos., 111, doi:10.1029/2005JD006083, 2006.

Miloshevich, L. M., Vömel, H., Whiteman, D., and Leblanc, T.: Accuracy assessment and correction of Vaisala RS92 radiosonde water vapor measurements, J. Geophys. Res.-Atmos., 114, D11305, doi:10.1029/2008JD011565, 2009. 
Moradi, I., Soden, B., Ferraro, R., Arkin, P., and Vömel, H.: Assessing the quality of humidity measurements from global operational radiosonde sensors, J. Geophys. Res.-Atmos., 118, 80408053, doi:10.1002/jgrd.50589, 2013.

Nash, J., Smout, R., Oakley, T., Pathack, B., and Kurnosenko, S.: WMO Intercomparison of Radiosonde Systems, Vacoas, Mauritius, 2-25 February 2005, Tech. rep., WMO, WMO/TD-No. 1303,2006

Nash, J., Oakley, T., Vömel, H., and Wei, L.: WMO Intercomparison of High Quality Radiosonde Systems Yangjiang, China, 12 July-3 August 2010, Tech. rep., WMO, https://www.wmo.int/pages/prog/www/IMOP/publications/ IOM-107Yangjiang/IOM-107_Yangjiang.zip (last access: December 2014), WMO/TD-No. 1580, Instruments And Observing Methods Report No. 107, 2011.

Salasmaa, E. and Kostamo, P.: New thin film humidity sensor, 3338, Amer. Meteor. Soc., Washington DC, 1975.

Seidel, D. J., Berger, F. H., Immler, F., Sommer, M., Vömel, H., Diamond, H. J., Dykema, J., Goodrich, D., Murray, W., Peterson, T., Sisterson, D., Thorne, P., and Wang, J.: Reference Upper-Air Observations for Climate: Rationale, Progress, and Plans, B. Am. Meteorol. Soc., 90, 361-369, 2009.

Sherwood, S. C., Meyer, C. L., Allen, R. J., and Titchner, H. A.: Robust tropospheric warming revealed by iteratively homogenized radiosonde data, J. Climate, 21, 5336-5350, 2008.

Shimizu, K. and Hasebe, F.: Fast-response high-resolution temperature sonde aimed at contamination-free profile observations, Atmos. Meas. Tech., 3, 1673-1681, doi:10.5194/amt-3-1673-2010, 2010

Smit, H., Kivi, R., Vömel, H., and Paukkunen, A.: Thin Film Capacitive Sensors, vol. 10 of ISSI Scientific Report Series/, Springer, New York, 11-38, 2013.

Sommer, M.: GRUAN Technical document 3 - User Guide of GRUAN RsLaunchClient, Tech. rep., GRUAN Lead Centre, Lindenberg, Germany, version 1.0, 2014.

Sun, B., Reale, A., Schroeder, S., Seidel, D. J., and Ballish, B.: Toward improved corrections for radiation-induced biases in radiosonde temperature observations, J. Geophys. Res.-Atmos., 118, 4231-4243, 2013.

Thorne, P. W., Brohan, P., Titchner, H. A., McCarthy, M. P., Sherwood, S. C., Peterson, T. C., Haimberger, L., Parker, D. E., Tett, S. F. B., Santer, B. D., Fereday, D. R., and Kennedy, J. J.: A quantification of uncertainties in historical tropical tropospheric temperature trends from radiosondes, J. Geophys. Res.-Atmos., 116, D12116, doi:10.1029/2010jd015487, 2011.
Thulin, A.: A "Standardized" Gravity Formula, OIML Bulletin, 127, 45, http://www.oiml.org/en/publications/bulletin/pdf/ 1992-bulletin-127.pdf (last access: December 2014), 1992.

Tiefenau, H. K. E. and Gebbeken, A.: Influence of Meteorological Balloons on Temperature Measurements with Radiosondes: Nighttime Cooling and Daylight Heating, J. Atmos. Ocean. Tech., 6, 36-42, 1989.

Turtiainen, H., Tammela, S., and Stuns, I.: A new radiosonde temperature sensor with fast response time and small radiation error, in: Ninth symposium on Meteorological Observations and Instrumentation, vol. 9, American Meteorological Society, Boston, MA, 60-64, 1995.

Vaisala: CAL4 Calibration machine Traceability and Uncertainty, Technical Document DOC210645, Vaisala DCO210645, 2002.

Vaisala: Vaisala Radiosonde RS92 Measurement Accuracy, Technical report, Vaisala, 2007.

Vaisala continuity website: Vaisala sounding data continuity website, http://www.vaisala.com/en/meteorology/products/ soundingsystemsandradiosondes/soundingdatacontinuity/Pages/ default.aspx, last access: 20 August 2013.

Vömel, H., David, D. E., and Smith, K.: Accuracy of tropospheric and stratospheric water vapor measurements by the cryogenic frost point hygrometer: Instrumental details and observations, J. Geophys. Res.-Atmos., 112, D08305, doi:10.1029/2006jd007224, 2007a.

Vömel, H., Selkirk, H., Miloshevich, L., Valverde-Canossa, J., Valdés, J., Kyrö, E., Kivi, R., Stolz, W., Peng, G., and Diaz, J. A. Radiation Dry Bias of the Vaisala RS92 Humidity Sensor, J. Atmos. Ocean. Tech., 24, 953-963, 2007b.

Whiteman, D. N., Russo, F., Demoz, B., Miloshevich, L. M., Veselovskii, I., Hannon, S., Wang, Z., Vömel, H., Schmidlin, F., Lesht, B., Moore, P. J., Beebe, A. S., Gambacorta, A., and Barnet, C.: Analysis of Raman lidar and radiosonde measurements from the AWEX-G field campaign and its relation to Aqua validation, J. Geophys. Res.-Atmos., 111, D09S09, doi:10.1029/2005JD006429, 2006.

WMO: Guide to Meteorological Instruments and Methods of Observation, World Meteorological Organization, 7th Edn., http:// library.wmo.int/pmb_ged/wmo_8_en-2012.pdf (last access: December 2014), 2008. 